\title{
CHINCHILLA DE MONTEARAGÓN Y EL DIEZMO ECLESIÁSTICO DE SU DISTRITO. SIGLOS XVII-XVIII
}

\section{CHINCHILLA DE MONTEARAGÓN AND THE ECLESIASTICAL TI- THE OF ITS DISTRICT. $17^{\mathrm{TH}}-18^{\mathrm{TH}}$ CENTURIES}

\author{
Vicente Montojo Montojo \\ Real Academia Alfonso X el Sabio \\ Murcia, Com. Aut. Región de Murcia, España \\ vicente.montojo@um.es
}

Cómo citar este artículo: Montojo Montojo, V. (2020). Chinchilla de Montearagón y el diezmo eclesiástico de su distrito. Al-Basit (65). 41-84. http://doi. org/10.37927/al-basit.65_2

Recibido/Received: 31-03-2020

Aceptado/Accepted: 20-06-2020

RESUMEN: Se trata en este texto la participación de la población de Chinchilla y otras de su distrito o corregimiento en la administración y gestión del diezmo eclesiástico en los siglos XVII y XVIII, una parte de la producción agraria que se entregaba a la Diócesis de Cartagena (obispo y cabildo catedralicio, con sede en Murcia) y al rey (tercias reales) o incluso al señor en el caso de los señoríos. Esta actuación poblacional en el diezmo eclesiástico se dio por parte de diversos grupos sociales, por lo que es ilustrativa de la organización social y de su evolución, en la que incidió la política de los gobiernos ilustrados del siglo XVIII por razón de
ABSTRACT: In this text, the participation of the population of Chinchilla and others of its district in the administration and management of ecclesiastical tithe in the 17th and 18th centuries, a part of the agrarian production that is delivered to the Diocese of Cartagena (bishop and council cathedral, based in Murcia) and the king (royal thirds) or even the lord in the case of manors. This popular action in the ecclesiastical tithe took place on the part of diverse social groups, reason why it is illustrative of the social organization and its evolution, in which the policy of the enlightened governments of the eighteenth century influenced 
la liberalización de los precios de los cereales (antes tasados) y de la fijación de nuevas contribuciones, como el fondo pío beneficial o los frutos civiles. De esta forma se da a conocer un poco más la composición social en Chinchilla, ciudad a la que no se le ha dedicado apenas atención en estos aspectos, sobre todo en el siglo XVIII.

La gestión y administración del diezmo eclesiástico se vio sometida a la confrontación de fuertes intereses materiales, tanto entre perceptores y contribuyentes, como entre los propios perceptores, pues algunos eran más absentistas que otros, pero también entre contribuyentes, pues los hubo que se aprovecharon de su proximidad al Reino de Valencia para desplazar sus productos sin pagar el diezmo, o de su doble vivienda. En este sentido se puede entender bien que permita esta investigación un conocimiento más variado de la composición social.

PALABRAS CLAVE: Historia Social. Historia Económica. Historia Moderna. Historia de España. Archivos. La Mancha. by the liberalization of the cereal prices (previously appraised) and the setting of new contributions, such as the pious fund and frutos civiles. In this way, the social composition of Chinchilla is made known a little more, a city to which hardly any attention has been devoted in these aspects.

In this way, the social composition of Chinchilla is made known a little more, a city to which hardly any attention has been devoted in these aspects, especially in the 18th century.

The management and administration of the ecclesiastical tithe was subjected to the confrontation of strong material interests, both between recipients and taxpayers, and between the recipients themselves, since some were more absentee than others, but also among taxpayers, since there were those who took advantage of its proximity to the Kingdom of Valencia to move its products without paying tithe, or its double home. In this sense, it can be well understood that this research allows a more varied knowledge of social composition.

KEY WORDS: Social History. Economic history. Modern history. Spain's History. Archives. La Mancha. 


\section{INTRODUCCIÓN}

En el siglo XVII la población de Chinchilla de Montearagón y su amplio corregimiento o distrito (Molina, 2005) fue sobre todo agraria (Montojo, 2019) y de aquí que en cierta manera se articulara en torno a la contribución del diezmo eclesiástico del arciprestazgo de Chinchilla en los siglos XVI-XVIII, por lo que éste puede bien ser un observatorio adecuado de investigación de historia socio-económica de Chinchilla de Montearagón y su distrito y, por lo tanto, el objeto de este artículo, desde una metodología histórico-archivística (Lodolini, 1993), que consiste sobre todo en identificar los productores de documentos y sus fondos y series, lo que permita un enfoque plural es decir no sólo económico sino también social a través de su indización.

La organización territorial diocesana se compuso de vicarías y arciprestazgos (García, 1988), que en los siglos XVI y XVII fue base de la civil, pues ésta no se desdobló en corregimientos hasta 1586, en partidos hasta $1691 \mathrm{ni}$ en provincias hasta 1718, salvo las del servicio de millones. En la Vicaría de Chinchilla, Alpera pasó a la de Almansa en 1676 (García, 2002). Pero además Chinchilla hubo de contribuir militarmente, así en 1611 con 560 soldados para la milicia; en 16181619 con una compañía de milicia de 200 hombres (Albacete con otra de 200 y Almansa con otra de 200; Hellín con 200, Tobarra 100) y en 1639/1646 con 8/13 soldados (Albacete: 12/23; Almansa: 7/10; Hellín: 8/20; Tobarra: 4/11) al socorrer Cartagena. En cambio: "la villa de Almansa, Tobarra, Albacete y ciudad de Chinchilla por inducción del corregidor se negaban a contribuir a la defensa de la obra [torres defensivas del Estacio y Pinatar, 1591] con los 100 hombres que le correspondía pagar al antiguo marquesado de Villena, durante 5 meses" (Ruiz, 1994, pp. 802, 950, 955 y 155). Hubo por tanto grandes dificultades, tales que pueden considerarse como el hilo conductor de los siglos XVII y XVIII.

\section{FUENTES DOCUMENTALES CHINCHILLANAS (SS.XVI-XVIII)}

\subsection{Documentación notarial}

En lo que se refiere al siglo XVI es sobre todo la documentación notarial, de mucho uso tradicionalmente entre historiadores (Eiras, 1984), la que nos aporta información sobre la movilidad de la población y sus relaciones con otros espacios, a partir de actas de obligaciones de pago y poderes de los protocolos de Murcia, Cartagena y Mazarrón del Archivo Histórico Provincial de Murcia (Montojo, 2007), entre otras poblaciones, de las que se han elegido aquellas por su posición 
geográfica marítima o capital y en los que se ha hecho un exhaustivo muestreo por razón de su uso con motivo de la tesis doctoral.

Por ejemplo, esta documentación refleja que grandes propietarios de Chinchilla contrataban trabajadores en Mazarrón para segar sus trigos, después de terminar la temporada de pesca (Vivanco, 1727, $6795 / 223$ ), o que vecinos de Chinchilla se desplazaron a Cartagena a comprar pescado (Borrás, 1578, 5159/569).

\subsection{Documentación decimal eclesiástica}

Pero podemos aproximarnos además a este tema en el XVII a través de quienes (colectores, administradores o fieles) gestionaron documentación eclesiástica decimal, utilizada hace muchos años por historiadores (Marcos, 1983; Juan, 1989; Rey, 1992, 1995 y 2010), tanto no contable como contable. Entre la primera están las actas capitulares del cabildo catedralicio de Murcia, conservadas en el Archivo Catedral de Murcia (ACM; García, 2014), en las que se anotaron anomalías y resoluciones de deudas (por ejemplo: Apéndice, 30.6.1617; desde ahora citaré sólo la fecha), como abusos de fieles administradores, arrendadores y mayordomos, entre éstos Gaspar Salafranca, mercader natural de Valencia que trabajó unos años en Cartagena antes de instalarse en Murcia (Montojo, 1995; Ruiz, 1994, pp.164, 416, 932). En este apartado están también las cartas (comunicaciones o correspondencia) y escrituras de fianzas.

El diezmo fue una contribución económica hecha por los productores a las tercias decimales eclesiásticas, de la que participaban el clero (obispo y cabildo, parroquias y sus fábricas), el rey (llamada tercias reales) y algunos señores jurisdiccionales y solariegos. En la parte percibida por el obispo y el cabildo catedralicio participaron arrendadores como gestores de rentas que remitieron al mayordomo del cabildo, generalmente un mercader, rentas tales como las de uva, ganado, lana y minucias (18.9.1620), que cuando se retrasaron les apremiaron a pagar y les pusieron ejecución o embargo (4.9.1618).

\subsection{Escriturar y contabilizar: actas, cuentas y escrituras}

Las actas, cuentas y escrituras de diezmos engrosaron el archivo de la fábrica (18.11.1616). Algo muy parecido a lo que sucedió en la esfera civil en recaudaciones de servicios fiscales votados en las cortes, como los de cortes y millones.

Pero los arrendadores fueron incluso miembros de oligarquías, como Pedro Tomás Carrasco Ramírez de Arellano, de La Roda y Villarrobledo (Cózar, 2008, p. 44). Hubo tal variedad de perceptores y partícipes, que obliga a conocer su tipología y al mismo tiempo nos muestra la compleja articulación social que supuso su gestión. 
Pues, aunque los fieles colectores fueron clérigos y administraron directamente, coincidieron con arrendadores laicos (así Las Peñas, 21.8.1618), puesto que algunos productos se arrendaban, además de que sus fiadores eran laicos. En las actas del cabildo se da fe de la extensión de la plaga de la langosta de 1620 (6.4.1619, 22.5.1620) por todo el territorio, incluso con controversia en Las Peñas (27.10.1620), que fue otra manifestación de una gran crisis económica.

Además, colectores, fieles y arrendadores dieron siempre fianzas (en forma de escrituras) de los dezmatorios o territorios con tercia decimal (o lugar de recogida del diezmo), aunque las fianzas se insertaron también en los registros de los escribanos o protocolos notariales, como si fueran actas. Este tipo de documentos ofrece una imagen dinámica de la evolución económica, a diferencia de la fija del Catastro de Ensenada.

Los fieles dezmeros o de los graneros llevaron periódicamente sus libros de cuentas de diezmos al cabildo, salvo casos imponderables, como al principio del reinado de Felipe IV y del valimiento del conde duque de Olivares (19.8.1622), pero el concejo de Chinchilla influyó en las existencias de cereales por sus peticiones de grano (23.9.1622), a las que se añadieron otros concejos, como Yecla y Las Peñas (4.11 y 6.12.1622; de Yecla se arrendó su renta en 33.000 reales por 3 años: 19.5.1623), síntoma de carestía.

Además, el trabajo de recolección obligó a recurrir a transportistas: numerosos arrieros y carreteros manchegos que transportaron aceite de Cartagena por La Mancha (Salomon, 1982) y cereales de regreso a Murcia.

Por entonces los fieles laicos de las tercias sufrieron extorsiones de jueces ejecutores, que pretendieron pagar así la quema de la langosta que infectó (4.12.1618), y algunos conventos de religiosos tendieron a eximirse del diezmo, como agustinos en Albacete o monjas clarisas de Hellín (10.1 y 7.2.1617, 13.9 y 9.7.1619). Hubo queja además de la venta tan barata del ganado de Albacete (6.12.1619), o los malos años incitaron a los arrendadores a pedir reducciones de pagos o sueltas (27 y 30.10 .1620 ) y se les dio demora de la $1^{\text {a }}$ paga a Pascua de 1621 y de la $2^{\text {a }}$ a Todos los santos (3/6.11 y 22.12.1620). Es ésta otra muestra de la tensión social en torno al diezmo, pues muchos tendieron a eximirse. Todo ello se refleja en las actas y la correspondencia del cabildo.

En 1630 el cabildo de Murcia (Irigoyen, 2001; Cánovas, 1994) requirió a los fieles de tercias de Chinchilla $(6.9 .1616 ; 680 / 9-7,8,1630)$ el reparto de sus frutos, pues se denunciaron los muchos excesos que se hacían en las tercias del obispado, según requerimientos del administrador Bartolomé de Oliva del Real al licenciado Jerónimo de Arboleda, arcipreste, Juan Valero Molina, Alonso Cano Manuel y Marcos de 
Poveda, regidor, fieles de Chinchilla (alegaron que fue embargado por el corregidor).

La primera cuenta es precisamente la de 1630, cuando se denunciaron abusos en las tercias, en las Peñas $(27.6,4.7,8.8,5.9,17.10$, $3 / 7.11 .1623$ ), como las hubo en la corte en años anteriores contra los duques de Uceda y Lerma (1617-1621) y sus criaturas o en éstos contra el conde duque de Olivares. El cabildo vigiló a fieles y arrendadores y que los fieles no fueran a la vez colectores, por problemas de malversación.

La cuenta de Chinchilla recogió la venta de una parte del trigo a los pósitos de Chinchilla y Murcia (al primero 304 fanegas de trigo rubión a 3 ducados/1 en 1649 y 183 en 1650 y 300 al de Murcia a 26 reales/1: ACM, 720/69, fs. 24-27; Olivares, 1993), que abarcó a Albacete (24 y 28.9.1621, 17.5.1622) y La Gineta. Después resultó que se dio cebada y pidieron trigo, pero el cabildo se negó y nombró colector a Bartolomé Pastor (26.9 y 10.10.1617) (Imagen p. 84). En Chinchilla hubo un gran conflicto en el concejo en 1635 (AHN, Cons.31833/12).

\subsection{Subsidio y excusado: servicios o gracias del clero al rey}

Al diezmo se añadió la recaudación regia del subsidio y excusado, que pagó el clero y se prorrogó cada 5 años, servicio que consiguió Felipe II para financiar la escuadra de Galeras de España (Domínguez, 1985, 359-382; 12, 25.9.1616), y dio problemas al extenderlo al voto de Santiago, otra contribución eclesiástica (8.5 y 2.6.1620) y recaudó el genovés Carlos Strata (4.1.1622; Álvarez, 1999, p. 525-527).

\section{EVOLUCIÓN EN LA SEGUNDA MITAD DEL XVII}

Destacaría en ella (y con ello nos adentramos en otro aspecto, el de la historia social de la familia) la introducción de fiadores y arrendadores de Chinchilla y Albacete del apellido Cantos (Cózar, 2008), que se prolongó en el XVIII. Las primeras fianzas que he encontrado en el archivo catedralicio son de 1693 en adelante, a favor del cabildo catedralicio. En la de 1693 hipotecaron propiedades inmuebles (10.10.1623), pero sin agua de fuente, sino tierras de trigales y cebadales situadas en heredamientos, a veces enteros, o de viñedos, incluso jóvenes o majuelos, éstos en el ejido de Chinchilla, de secano. Estas gestiones se hicieron ante la contaduría del cabildo órgano que fue instancia intermedia para administradores y arrendadores periféricos. 


\section{Cuadro 1. Fianzas de José Ruiz Amoraga (Sobre éste: Lacy, 2002)}

\begin{tabular}{|c|c|c|c|c|}
\hline $\begin{array}{l}\text { Otorgante } \\
\text { fianza }\end{array}$ & cant. & Cultivo/propiedad/lugar & Otra propiedad & Rls. \\
\hline \multirow[t]{4}{*}{$\begin{array}{c}\text { José Ruiz } \\
\text { Amoraga y } \\
\text { madre }\end{array}$} & 800 & $\begin{array}{l}\text { almudes: trigal } 1 / 2 \text { her. } \\
\text { Orán }\end{array}$ & $\begin{array}{c}\text { Heredamiento. } \\
\text { Torre Bujía/Pozo } \\
\text { Angosto }\end{array}$ & 11000 \\
\hline & & vides del viñedo: 5.000 rls. & $\begin{array}{l}2 \text { casas Chinchi- } \\
\text { lla }\end{array}$ & 7700 \\
\hline & & almazara ejido Chinchilla & $\begin{array}{l}\text { casa tinte, cal- } \\
\text { deras, balsas y } \\
\text { cebadal }\end{array}$ & 4400 \\
\hline & 200 & $\begin{array}{l}\text { almudes tierra ejido Chin- } \\
\text { chilla }\end{array}$ & & \\
\hline \multirow[t]{3}{*}{$\begin{array}{l}\text { Domingo } \\
\text { Ruiz Amo- } \\
\text { raga }\end{array}$} & 700 & $\begin{array}{l}\text { almudes: trigal } 1 / 2 \text { hereda- } \\
\text { miento. Orán }\end{array}$ & & 10000 \\
\hline & 5500 & $\begin{array}{c}\text { reales: } 1 \text { casa Chinchilla jto. } \\
\text { muralla }\end{array}$ & & \\
\hline & 100 & $\begin{array}{l}\text { almudes cebadales ejido } \\
\text { Chinchilla }\end{array}$ & & 1100 \\
\hline \multirow[t]{2}{*}{$\begin{array}{l}\text { José de Mo- } \\
\text { lina }\end{array}$} & 500 & $\begin{array}{c}\text { almudes heredmto. Casa } \\
\text { Paredes }\end{array}$ & & 4400 \\
\hline & 4000 & $\begin{array}{c}\text { vides del Cerrillo por } 2.200 \\
\text { reales }\end{array}$ & $\begin{array}{l}\text { casa en Chin- } \\
\text { chilla }\end{array}$ & 4400 \\
\hline $\begin{array}{l}\text { Mateo } \\
\text { López Santa }\end{array}$ & 900 & $\begin{array}{l}\text { almudes trigales: heredad } \\
\text { Cepero }\end{array}$ & $\begin{array}{l}\text { (Muñoz, 2010, p. } \\
\text { 337) }\end{array}$ & 12000 \\
\hline
\end{tabular}

Elaboración propia. Fuente: ACM, Legajos, 549/39, 4.1.1693

Ambas fianzas reflejan la importancia del cereal y la vid como cultivos, pero se hicieron en época de guerra, de mucha carga fiscal, que favoreció el contrabando de ganado, situación que se dio antes, pues vecinos de Las Peñas llevaron ganado a Calasparra en 1615 y hubo problemas en Peñas con el ganado de Pliego y Calasparra (26.8.1616, 19 y 26.9.1617). Así, Simón Jiménez de Heredia y Saavedra, de Chinchilla, y García Martínez y Amador González, de La Gineta, confiaron a Bartolomé Gascón, su defensa de denuncias de los oficiales de Miguel Pérez Pastor [de Vera], juez conservador de los puertos secos de Castilla, por tomarles carneros en Cañada Paja- 
res de Chinchilla (Archivo Histórico Provincial de Albacete o AHPAl, Notariado, no. 1.848, fs. 25 y 26, 18 y 20.10.1698; sobre este archivo: Pascual, 2002). Mateo López Santa fue heredero de Roca Vázquez, de Montealegre (Ídem, f. 186, 12.8.1708).

En la administración decimal de Chinchilla destacó alguno como Rodrigo de Cantos, de Albacete (17.10.1623), por su autoridad o poder, posiblemente el que figura como:

"el capitán Rodrigo de Cantos Royo, natural de Albacete [que] casó con $\mathrm{D}^{\mathrm{a}}$ Ana Sabuco Alfonso, natural de Alcaraz, hija de Jerónimo Sabuco y de $\mathrm{D}^{\mathrm{a}}$ María Alfonso, naturales de Alcaraz, hija de Rodrigo de Orgaz y Mari Ximénez, y él hijo de Miguel Sabuco y Ana David todos vecinos de Alcaraz", o su hijo "Rodrigo de Cantos Royo, corregidor de Molina, Requena y Ciudad Real, alcalde de la hermandad por el estado noble de San Clemente, año 1628; gozó también en Albacete donde nació; y el año 1650 el alcalde de corte Pedro de la Cantera Salazar mandó que no fuera preso por deudas, por ser hijodalgo, ante Bartolomé de Salazar escribano de provincia; casó con $\mathrm{D}^{\mathrm{a}}$ Ana de Villodre, natural de San Clemente".

(Real Academia de la Historia, Col. Salazar, 29/55).

El primer Rodrigo fue hijo de: "Rodrigo Royo, vezino de Albacete, [que] casó con $\mathrm{D}^{\mathrm{a}}$ Isabel de Cantos, natural como él de Albacete" (sobre los de Alcaraz: Pretel, 2019, y de los Cantos de Albacete y Chinchilla: Cózar, 2008, p. 46).

Destacó además Miguel Pérez Pastor, juez conservador de puertos secos o aduaneros, del que algunos herederos emigraron y prosperaron en Guadix y algún otro intentó ser señor de Pétrola (Lemeunier, 1994, p. 43; Rodríguez, 2012).

Se hicieron fianzas porque se buscó la seguridad y solvencia en los arrendamientos o las administraciones (o fieldades). Fue el caso de Francisco Núñez, labrador del heredamiento de Pozo la Higuera (Chinchilla), fiador, y Miguel Jiménez, vecino de La Gineta y natural de Chinchilla, principal, que se obligaron mutuamente en pagar una deuda al dominico Convento de San Juan Bautista, en que el $2^{\circ}$ litigó, quizá por tenerlas cedidas a censo, como Benito García (AHPAl, Not.1848/27-32, 20 y 30.10.1698); de lo que es un ejemplo que la fianza tuvo forma de obligación. Otro tipo de trabajo como el de recoger el cereal del diezmo, se contrató con un particular, como Bartolomé Ortega en 1699, sin fianza. Por lo tanto, hubo variedad entre los que trabajaron para las tercias.

Las fianzas se respaldaron mediante hipotecas de inmuebles, sobre todo tierras, pero algunas tierras se inmovilizaron por medio de capellanías y vínculos, por lo que pudo faltar tierra libre para arrendar y se acumularon las deudas. Otras tierras fueron sujetas a rentas de mi- 
sas perpetuas y aún de otras (muy minoritariamente) se perdió su dueño por emigración. Por otra parte, la constatación del poder otorgado desde Quintanar del Rey, situado en el corregimiento de San Clemente, hace percibir la extensión de las propiedades de vecinos y propietarios de Chinchilla en otras poblaciones, a causa de entronques familiares con vecinos de éstas y de herencias.

Otras veces interfirieron peticiones del obispado de Cartagena en la distribución, o de personas de fuera. La medida de trigo de Chinchilla era considerada como un ejemplo (15.12.1617), pero no todo era oro lo que relucía, pues se hicieron cosas mal hechas.

En Chinchilla la administración, beneficio y cobranza de frutos de los diezmos eclesiásticos atrajeron a sus propios vecinos y moradores en la renta de minucias (1699), aunque lo menudo era poca cosa, o igualmente algunos labradores del heredamiento de Hoya Gonzalo, que pleitearon por pretender pagar $1 / 9$ por labrar tierras ajenas, o algún valenciano de Enguera que se comprometió a transportar cereales a las tercias. Hubo mucho antes abusos y agravios entre los fieles dezmeros de Albacete (23.2.1617), que provocaron numerosos pleitos o litigios.

En la composición de los patrimonios de los fiadores se observa el predominio de cereal, pero se cosechó cáñamo, que estuvo por agramar en 1698 (ACM, 346/50, 21.10.1713), y azafrán, del que luego trataré.

Cuadro 2. Cuentas del diezmo de Chinchilla (1698) y Tobarra (1707)

\begin{tabular}{|l|r|r|r|r|r|}
\hline Cultivo & 1698 fans. & 1698 rls. & 1707 fans. & rls./1 & 1707 rls. \\
\hline Trigo & 76,8 & 2146,23 & 31 & 28 & 868 \\
\hline Cebada & 32,2 & 375 & 32 & 12 o 13 & 404 \\
\hline Centeno & 7 & 105 & 7,5 & 15 & 127,5 \\
\hline Avena & & & 0,5 & & 3 \\
\hline Cañamones & 2,3 & 38,8 & 6 & 15 o 17 & 90 \\
\hline Cáñamo & 21 & 322,5 & 30 & 15 & 450 \\
\hline $\begin{array}{l}\text { Hoja } 1698 \text { /corderos } \\
1707\end{array}$ & & 8 & 19 & 10 & 195,2 \\
\hline Total ingresos o cargo & & 3007,14 & & & 2137,7 \\
\hline Total data o gastos & & 2995,53 & & & 412,25 \\
\hline
\end{tabular}

Fuente: ACM, Legajo, 596/20 
Se advierte en este cuadro 2 el peso tan enorme de los cereales y la incipiente presencia de cáñamo y cañamón ${ }^{2}$ en ambas poblaciones, que poco después se vendió en Alicante.

\section{LA PRIMERA MITAD DEL SIGLO XVIII}

Los primeros años del siglo XVIII fueron los de la Guerra de Sucesión española (1702-1715), en que hubo epidemia y hambrunas, a los que siguieron otras guerras durante casi todo el reinado de Felipe V, que transcurrió en revisión del Tratado de Utrecht (1713) y siguientes (Sevilla, 1720) con el fin de recuperar los territorios italianos que pertenecieron a España hasta 1713, a fin de que reinaran en ellos los hijos de Isabel de Farnesio, heredera de los derechos de sucesión del ducado de Parma, y en ellos se reclutaron soldados para el ejército ( 3 soldados para el del duque de San Juan, según poder del concejo: 4.6.1708), además de darse acciones de guerra en torno a la batalla de Almansa, de las que algunos fueron premiados (Muñoz, 2010, pp. 92, 146, 247, 302).

Se hicieron reformas internas, pues en fiscalidad se introdujeron nuevas contribuciones como la de cuarteles y utensilios en Castilla, catastro en Cataluña, talla en Aragón, equivalente en Valencia, lo que dio lugar a numerosas revisiones y desórdenes. Permaneció además la cíclica crisis demográfica y económica, en forma de epidemias y hambrunas (Cebrián, 2019, p. 44), de manera que algunos vecinos acumularon numerosas deudas: Juan Valero pidió moratoria y aunque el obispo Luís Belluga hizo socorros hubo muchos deudores (Cuadro 3).

Cuadro 3. Deudores de diezmos (1713-1750)

\begin{tabular}{|c|c|c|c|c|c|c|c|}
\hline Deudores & $\begin{array}{l}\text { Reales/ } \\
\text { Fanegas }\end{array}$ & Concepto & Fecha & $\begin{array}{c}\text { Observa- } \\
\text { ciones }\end{array}$ & & & \\
\hline $\begin{array}{l}\text { Bartolomé } \\
\text { López }\end{array}$ & 199 & $\begin{array}{c}\text { ganado } \\
\text { dezmeño de } \\
1709\end{array}$ & 1713 & $\begin{array}{l}\text { Tribunal } \\
\text { de la } \\
\text { Cruzada }\end{array}$ & & $\begin{array}{l}\text { Francisco } \\
\text { Antonio, } \\
\text { Mercadillos }\end{array}$ & 1731 \\
\hline $\begin{array}{c}\text { Juan Gómez } \\
\text { Poveda }\end{array}$ & 15850 & minucias & $\begin{array}{l}1717- \\
1718 \\
\end{array}$ & $\begin{array}{c}\text { ACM } \\
603,11 \\
\end{array}$ & & $\begin{array}{l}\text { Pascual } \\
\text { Sánchez }\end{array}$ & 1731 \\
\hline $\begin{array}{c}\text { Francisco } \\
\text { García y Ma- } \\
\text { rina García } \\
\text { viuda }\end{array}$ & 468,17 & fiel tercería & $\begin{array}{l}1715 \\
1721\end{array}$ & & & $\begin{array}{l}\text { Juan de } \\
\text { Ortega }\end{array}$ & 1731 \\
\hline Juan de Ávila & $\begin{array}{c}1.147^{\prime} 5 \\
\mathrm{x} 153\end{array}$ & $\begin{array}{l}\text { diezmo de } \\
\text { cebada }\end{array}$ & 1716 & & & $\begin{array}{l}\text { Juan Caste- } \\
\text { llano }\end{array}$ & 1731 \\
\hline $\begin{array}{c}\text { Pedro Núñez } \\
\text { Flores } \\
\text { Regidor }\end{array}$ & $\begin{array}{l}708 x \\
59\end{array}$ & $\begin{array}{l}\text { trigo, cente- } \\
\text { no y cebada }\end{array}$ & 1716 & $\begin{array}{c}\text { Julián } \\
\text { Cortijo } \\
\text { escriba- } \\
\text { no } \\
\end{array}$ & & $\begin{array}{l}\text { Blas Mar- } \\
\text { tínez }\end{array}$ & 1731 \\
\hline $\begin{array}{l}\text { Juan Cer- } \\
\text { dán, Miguel } \\
\text { Romero }\end{array}$ & $\begin{array}{c}272 x \\
16\end{array}$ & $\begin{array}{l}\text { trigo total } \\
1887,5 \text { rls. }\end{array}$ & 1718 & $\begin{array}{l}\text { Benito } \\
\text { López } \\
\text { ACM } \\
362 / 42\end{array}$ & $\begin{array}{l}\text { Car- } \\
\text { celén }\end{array}$ & $\begin{array}{l}\text { Pedro } \\
\text { Sánchez } \\
\text { Madrona }\end{array}$ & 1731 \\
\hline
\end{tabular}

${ }^{2}$ Se cultivó en Caravaca: Arrendamiento de Juan Navarro Albizu, AHPM, Not. 7514/57, 31.1.1724. 


\begin{tabular}{|c|c|c|c|c|c|c|c|c|}
\hline $\begin{array}{c}\text { Manuel de } \\
\text { Cañas Cortés } \\
\text { Reina y Silva }\end{array}$ & $\begin{array}{l}\text { Corral } \\
\text { Rubio }\end{array}$ & $\begin{array}{l}\text { subsidio y } \\
\text { excusado }\end{array}$ & 1720 & & $\begin{array}{l}\text { Francisco } \\
\text { Sánchez } \\
\text { Madrona }\end{array}$ & & & 1731 \\
\hline $\begin{array}{l}\text { Miguel } \\
\text { García }\end{array}$ & El Villar & $\begin{array}{c}785,17 \\
\text { de lana y } \\
\text { ganado }\end{array}$ & 1721 & & $\begin{array}{l}\text { Juan de } \\
\text { Ruescas }\end{array}$ & & & 1731 \\
\hline $\begin{array}{l}\text { Eugenio } \\
\text { Madrona }\end{array}$ & 66,28 & minucias & $\begin{array}{l}1723 \\
1725\end{array}$ & & $\begin{array}{c}\text { Francisco } \\
\text { García } \\
\text { Moreno }\end{array}$ & & & 1731 \\
\hline $\begin{array}{l}\text { Juan Pala- } \\
\text { cios }\end{array}$ & 603 & uva & 1726 & & $\begin{array}{l}\text { Simón Cano } \\
\text { menor }\end{array}$ & & & 1731 \\
\hline $\begin{array}{c}\text { Diego Martí- } \\
\text { nez Soto }\end{array}$ & 137,17 & $\begin{array}{c}\text { diezmo } \\
\text { Higueruela }\end{array}$ & 1727 & & $\begin{array}{l}\text { Miguel de } \\
\text { Alcaraz }\end{array}$ & & & 1731 \\
\hline $\begin{array}{l}\text { Pascual } \\
\text { García }\end{array}$ & 800 & $\begin{array}{l}\text { diezmo } \\
\text { Tinajeros }\end{array}$ & 1727 & & $\begin{array}{c}\text { Francisca } \\
\text { de Córdoba, } \\
\text { viuda de } \\
\text { Martín de } \\
\text { Villanueva } \\
\end{array}$ & 800 & $\begin{array}{l}\text { ga- } \\
\text { nado } \\
\text { enfer- } \\
\text { mo }\end{array}$ & 1731 \\
\hline $\begin{array}{c}\text { Alonso } \\
\text { Romero, de } \\
\text { Chinchilla }\end{array}$ & 641 & $\begin{array}{c}\text { minucias de } \\
1722 \\
\end{array}$ & 1728 & $\begin{array}{c}\text { ACM, } \\
364 / 13 \\
\end{array}$ & $\begin{array}{l}\text { Pedro Sán- } \\
\text { chez Cano }\end{array}$ & 172 & $\begin{array}{c}\operatorname{minu}- \\
\text { cias }\end{array}$ & 1731 \\
\hline $\begin{array}{l}\text { Sebastián } \\
\text { Gómez, } \\
\text { Chinchilla }\end{array}$ & 641 & $\begin{array}{l}\text { minucias } \\
\text { de } 1722\end{array}$ & 1728 & $\begin{array}{c}\text { ACM, } \\
364 / 13\end{array}$ & $\begin{array}{c}\text { Blas y } \\
\text { Pedro Mar- } \\
\text { tínez Don } \\
\text { Pedro } \\
\end{array}$ & 4374,2 & $\begin{array}{c}\operatorname{minu}- \\
\text { cias y } \\
\text { uva }\end{array}$ & $\begin{array}{c}1731 / \\
1733\end{array}$ \\
\hline $\begin{array}{l}\text { Francisco } \\
\text { Tobarra y } \\
\text { consortes }\end{array}$ & 641 & $\begin{array}{l}\text { minucias } \\
\text { de } 1722\end{array}$ & 1728 & $\begin{array}{c}\text { ACM, } \\
364 / 13\end{array}$ & $\begin{array}{c}\text { Francisco } \\
\text { Arenas } \\
\text { arriero } \\
\end{array}$ & 24 & $\begin{array}{c}\text { diez- } \\
\text { mo } \\
\text { fiado } \\
\end{array}$ & 1733 \\
\hline $\begin{array}{c}\text { Francisco } \\
\text { Tobarra } \\
\text { Valera } \\
\end{array}$ & & & 1731 & $\begin{array}{c}\text { ACM, } \\
362 / 27\end{array}$ & $\begin{array}{l}\text { Julián } \\
\text { Simón }\end{array}$ & 24 & $\begin{array}{l}\text { diez- } \\
\text { mo } \\
\text { fiado }\end{array}$ & 1733 \\
\hline $\begin{array}{c}\text { Antonio } \\
\text { Gómez }\end{array}$ & & & 1731 & $\begin{array}{c}\text { José } \\
\text { García } \\
\text { del Rey }\end{array}$ & $\begin{array}{l}\text { Benito } \\
\text { García }\end{array}$ & 144 & $\begin{array}{c}\text { diez- } \\
\text { mo } \\
\text { fiado }\end{array}$ & 1733 \\
\hline $\begin{array}{l}\text { Ignacio } \\
\text { Lencina }\end{array}$ & & & 1731 & & Juan Gómez & 12 & $\begin{array}{l}\text { diez- } \\
\text { mo } \\
\text { fiado }\end{array}$ & 1733 \\
\hline Blas Gómez & & & 1731 & & $\begin{array}{c}\text { Ana María } \\
\text { la fiscala }\end{array}$ & 30 & $\begin{array}{l}\text { diez- } \\
\text { mo } \\
\text { fiado }\end{array}$ & 1733 \\
\hline $\begin{array}{l}\text { Gregorio } \\
\text { Escobar }\end{array}$ & & & 1731 & & $\begin{array}{l}\text { Fernando } \\
\text { Molina, } \\
\text { presbítero }\end{array}$ & 86 & uva & 1733 \\
\hline $\begin{array}{c}\text { José Sánchez } \\
\text { mayor y } \\
\text { menor }\end{array}$ & & & 1731 & & $\begin{array}{c}\text { Pedro } \\
\text { Martínez } \\
\text { Sánchez }\end{array}$ & $7.477,17$ & $\begin{array}{c}\text { minu- } \\
\text { cias y } \\
\text { uva } \\
\end{array}$ & 1734 \\
\hline $\begin{array}{l}\text { Salvador } \\
\text { Martínez }\end{array}$ & & & 1731 & & $\begin{array}{l}\text { Juan Ruiz } \\
\text { Carrasco }\end{array}$ & $\begin{array}{c}5.405 \\
\text { de } 160 \\
\text { fanegas, } \\
8 \text { celemi- } \\
\text { nes y } 2 / 4 \\
\text { de trigo } \\
\text { a } 24 \\
\text { reales } / 1\end{array}$ & $\begin{array}{l}\text { subsi- } \\
\text { dio }\end{array}$ & 1735 \\
\hline $\begin{array}{l}\text { Tomás Cano, } \\
\text { del Campillo }\end{array}$ & & & 1731 & & $\begin{array}{c}\text { Francisco } \\
\text { Arenas } \\
\text { López }\end{array}$ & $\begin{array}{l}\text { Blas } \\
\text { Sánchez }\end{array}$ & $\begin{array}{l}\text { Vi- } \\
\text { cente } \\
\text { Pra- } \\
\text { das } \\
\end{array}$ & 1746 \\
\hline
\end{tabular}

Elaboración propia. Fuente: ACM, Legajos, Cuentas y expedientes de apremio 
Más concretamente el clima impuso sus circunstancias y de aquí que surgieran endeudamientos e impagos; pero antes otros de Chinchilla aprovecharon para arrendar el diezmo del vino de villas del corregimiento de San Clemente, quizá para acumular stocks; y otros (incluso de Yecla) compraron ganado, que podía moverse.

Continuó el contrabando de ganado, por ejemplo, de Barrax a Hellín, que no fue registrado en la aduana de Chinchilla. Si bien algunos labradores se endeudaron otros prosperaron, como una vez pasada la guerra Antonio Gabaldón y Molina, presbítero y comisario del Santo Oficio, como principal administrador de las tercias (1716).

Labradores de los heredamientos de Aldeanueva y Pozo Cañada se obligaron como fiadores a favor del cabildo de Murcia, es decir, personas acomodadas y de caudal, tras su subasta; o del fielato de tercias y administración de quinta casa a Miguel Antonio de Molina, fiscal eclesiástico de Chinchilla, y a los primeros sucedieron Francisco Javier de Cantos Gabaldón, nuevamente otro Cantos de Albacete, de larga tradición.

La producción de cereal alimentó su molturación por molinos como el de los Haces. Se puede entender así mejor que: "Chinchilla responde al proceso contrario, [...] mostrando que sus elites son todavía influyentes" (Cózar, 2014, p. 202).

Sí, pues hubo laicos generalmente poderosos, entre los perceptores de diezmos, como los Haro y otros de Chinchilla (sobre ellos, Núñez Robres, Reina Núñez y Barnuevo: Molina, 2007a, p. 50-75), incluso en los molinos de Valdespinar de Alarcón.

A la muerte de Cantos los contadores de la mesa capitular nombraron a Francisco López Clares para tomar cuentas a sus herederos (ACM, 364/14, 22.10.1734). Por entonces un Cantos de Albacete defendió los intereses de Chinchilla (Cózar, 2008, p. 58).

A Cantos le sucedió Pablo Núñez Flores, clérigo de menores órdenes, de importante familia, y sus fiadores, con bienes formados por piezas más pequeñas de tierras, llamadas cebadales, hazas de 3 a 20 almudes (medida usada en Toledo), con abundantes vides y algunas bodegas; a su favor testificó Juan Ballesteros, regidor, lo que muestra que se almacenó vino para su venta (sobre su tradición: 19.8.1616, o en 1768 Antonio Carrasco, regidor de Albacete, declaró 350 arrobas de vino: ACM, 640/4, 1768-1769). En 1721 hubo gastos de 568'8 reales (34 mrs.= 1 rl.) del salario, 1.392'3 de reparos del granero; el administrador de la 5a casa fue el regidor Juan García de la Atalaya (ACM, $546 / 42-44$ y $56,1720,1722$ y 1733 ), quien muestra otro grupo social el de los regidores.

Otros fieles de Chinchilla (José de Molina), de tercias del rey, se dirigieron a San Clemente, cabeza del otro corregimiento que hasta 1586 formó el partido de arriba del marquesado de Villlena. 
Este modo de actuar (el de los propios grandes y medianos propietarios que monopolizaron los arrendamientos de los diezmos eclesiásticos) es comparable al de los de Cartagena que con el carácter de comerciantes lo hicieron cara a la exportación de barrilla y vino, productos comercializables como los cereales.

\section{RESULTADOS RECAUDATORIOS DE DIEZMOS ECLESIÁSTICOS}

¿Cuáles fueron los resultados? Las cuentas del diezmo del cabildo de 1721, 1743, 1746 y 1750 (ACM, 619/15, 1721; 690/27, 1743; y $437 / 36,1750$ ) dieron lo que indica el cuadro 5 , a lo que se puede añadir para 1701-1707 la cuenta de la 5 a casa (cuadro 4: ACM, 595/15, 17011702). En 1704 la 5 a casa fue la de Fernando Angulo y Barnuevo, que incluyó sus haciendas de Losilla, Almagra y Villarejo, es decir, un gran propietario, y más tarde se desdobló por contribuyentes (1722), lo que permite una primera aproximación a la producción agraria (Bringas, 2012). Se nota en el cuadro 5 un crecimiento de 1721 a 1750, es decir, desde el final de la Guerra de Sucesión española al de la austriaca (Paz de Aquisgrán, 1748).

\section{Cuadro 4. Producto del diezmo de Chinchilla de la 5a}

(1701-1707)

\begin{tabular}{|c|c|c|c|c|c|c|c|}
\hline Chinchilla & 1699 & 1702 & 1703 & 1704 & 1705 & 1706 & 1707 \\
\hline $\begin{array}{c}\text { lana } \\
\text { prieta } \\
\text { (arrobas) }\end{array}$ & $14 / 24 / 340$ & $3 / 24 / 72$ & $3 / 20 / 75$ & $3 / 20 / 65$ & $4 / 20 / 85$ & $4 / 20 / 83$ & $4 / 20 / 82$ \\
\hline $\begin{array}{l}\text { lana } \\
\text { blanca } \\
\text { (ídem) }\end{array}$ & $1 / 34 / 51$ & $1 / 34 / 34$ & $0,18 / 30 / 22,17$ & $0,20 / 30 / 28$ & $1 / 30 / 37$ & $0,9 / x / 10,2$ & $0,24 / x / 29$ \\
\hline $\begin{array}{c}\text { ganado } \\
\text { (cabezas) }\end{array}$ & $87 / 9 / 783$ & $61 / 14 / 869$ & $55 / 12,5 / 687$ & $25 / 9 / 225$ & $62 / 9 / 558$ & $7 / 7 / 49$ & $52 / 10 / 520$ \\
\hline $\begin{array}{c}\text { trigo } \\
\text { (fanegas) }\end{array}$ & $11 / 28 / 322$ & $180 / 28 / 5042$ & $143 / 27 / 2879$ & $269 / 17 / 4401$ & $125 / 22 / 2761$ & $228 / 22 / 5021$ & $310 / 24 / 7500$ \\
\hline $\begin{array}{c}\text { trigo } \\
\text { centenoso } \\
\text { (ídem) }\end{array}$ & & $47 / 28 / 1318$ & & $0^{\prime} 5$ & & & \\
\hline $\begin{array}{c}\text { centeno } \\
\text { (ídem) }\end{array}$ & $3 / 17 / 62$ & $32 / 17 / 551$ & $57 / 14 / 806$ & $105 / 11 / 1097$ & $49 / 13,5 / 668$ & $40 / 13,5 / 540$ & $70 / 14 / 980$ \\
\hline $\begin{array}{l}\text { cebada } \\
\text { (ídem) }\end{array}$ & $16 / 11 / 176$ & $25 / 13 / 323$ & $43 / 10 / 417$ & $178 / 7 / 1113$ & $44 / 11 / 484$ & $166 / 11 / 1831$ & $179 / 12 / 2094$ \\
\hline $\begin{array}{l}\text { avena } \\
\text { (ídem) }\end{array}$ & $5 / 5,5 / 22$ & $25 / 6 / 150$ & $12,5 / 5 / 62$ & $22,5 / 3,5 / 79$ & $8,5 / 5,5 / 46$ & $18,5 / 5 / 92$ & $52 / 6 / 312$ \\
\hline $\begin{array}{c}\text { minucias } \\
\text { (reales) }\end{array}$ & & & 5 & & & & \\
\hline $\begin{array}{l}\text { azafrán } \\
\text { (onzas) }\end{array}$ & & 50 & & & & & \\
\hline
\end{tabular}




\begin{tabular}{|c|l|l|l|l|l|l|l|}
\hline aceite & & 50 & & & & & \\
\hline guijas & & & & $0,5 / 24 / 12$ & & & \\
\hline total (rls.) & & & 9907 & & & & \\
\hline
\end{tabular}

Elaboración propia. Fuente: ACM, Legajos, Cuentas de tazmías

En los primeros años se añadieron injerencias exteriores en su percepción, como en 1709 la de Domingo de Echenique, beneficiado navarro (otros navarros destacaron entonces como financieros) de la Iglesia de Santa María de Chinchilla y canónigo de la Catedral de Sigüenza, que reclamó su turno de fiel de tercias con sus gajes y emolumentos, para lo que apoderó a Juan Escolano, beneficiado como él, junto con Nicolás Avellaneda y Pedro Andrés Molina, en contra de Luís Fernández de Córdoba y La Cerda, caballero de Santiago y clérigo de órdenes menores, que poseía beneficios simples de las parroquias de Chinchilla, Tobarra y Jumilla y apoderó a José Ezpeleta.

El arcipreste de Chinchilla fue Antonio Núñez Reina, natural de ella, quien abrió el archivo y probó que desde 1630 y 1648 en libros de tercias y cuentas figuraron siempre fieles terceros, justificándose en una carta de los contadores. El proceso pasó al Consejo de Gobernación del Arzobispado de Toledo por apelación de los 3 beneficiados:

y habiendo buscado libros y cuentas más antiguas se han hallado rotas, que dijeron los fieles que al tiempo que se hizo el archivo que hay hoy estaban destropeadas de los antiguos, digo de los ratones y para obviar este daño se hizo dicho archivo, por cuya razón no se puede sacar razón de más tiempo (ACM, 540/30, 1709-1711).

En 1715 se advierte asimismo la potestad de Toledo pues el colector negoció el diezmo de lana con el cabildo, como mucho antes: "se les ha notificado un despacho de Toledo ... se participe al procurador que tienen en Toledo" (17.7.1618, 9.11.1621).

Entre los cultivos y sus frutos destacaron los cereales en Chinchilla, pero en la cuenta de tazmía de Ramiro Antonio Barnuevo (1722) hubo de minucias: 9 libras de miel en 7 reales, 1 libra y 2 onzas de uva en 5,10 y 50 reales de la huerta, total 62,10 (ACM, 640/28, 1722 y 1723), producción parecida en cierto modo a la de Yecla (Carpena, 2019, pp. 25-30).

Cuadro 5 Cuentas de tazmía del diezmo de Chinchilla (1716-1750).

\begin{tabular}{|c|c|c|c|c|c|c|c|c|c|c|}
\hline CHINCHILLA & $1716 \_1720$ & arrobas/fan & 1716 & 1717 & 1718 & 1719 & 1720 & 1721 & rls./1 & total rls. \\
\hline lana prieta (@) & 11621 & 570 & 120 & 105 & 120 & 105 & 120 & & 18 & 701 \\
\hline
\end{tabular}




\begin{tabular}{|c|c|c|c|c|c|c|c|c|c|c|}
\hline lana blanca (@) & & 49 & 4,2 & 6 & 12 & 12 & 15 & & 18 & 154 \\
\hline ganado (cabezas) & 62700 & 6270 & 1170 & 1290 & 1560 & 840 & 1410 & 300 & 10 & 3.150 \\
\hline trigo (fanegas) & 420337 & 28022 & 6750 & 8435 & 6435 & 420 & 5982 & 1625 & 15 & \\
\hline mal trigo (fanegas) & 34890 & 2907 & 70 & 30 & 0 & 2605 & 202 & 62 & 12 & 868 \\
\hline centeno (fanegas) & 147600 & 14760 & 2835 & 2835 & 2753 & 2910 & 3427 & 1188 & 10 & 11885 \\
\hline cebada (fanegas) & 135420 & 22570 & 4860 & 4395 & 2850 & 6135 & 4330 & 1463 & 6 & 9933 \\
\hline avena (fanegas) & 7400 & 1850 & 230 & 330 & 150 & 900 & 240 & 228 & 4 & 912 \\
\hline minucias (reales) & & & & & & & & & & \\
\hline azafrán (onzas) & & & & & & & & & & \\
\hline total (rls.) & 819968 & 709838 & & & & & & & & 24.455 \\
\hline data / gastos & 110130 & & 26250 & 15000 & 24000 & 19500 & 25380 & & & 8.963 \\
\hline
\end{tabular}

Como vemos en este cuadro los precios de la lana subieron de 18 a 30 reales la arroba, del trigo de 16 a 28, del centeno de 14 a 2, de cebada de 8 a 18 y de avena de 6 a 9, lo que indica una coyuntura alcista.

\begin{tabular}{|l|c|c|c|c|c|c|c|c|c|c|c|}
\hline CHINCHILLA & 1717 & $\begin{array}{c}\text { total } \\
\text { rls. }\end{array}$ & 1743 & rls./1 & total rs. & 1746 & rs./1 & $\begin{array}{c}\text { total } \\
\text { rs. }\end{array}$ & 1750 & rs./1 & total rs. \\
\hline $\begin{array}{l}\text { lana } \\
\text { prieta (@) }\end{array}$ & 17 & 282 & 72 & 27 & 2.181 & 77 & 30 & 2310 & 72 & 30 & 2.181 \\
\hline $\begin{array}{l}\text { lana } \\
\text { blanca (@) }\end{array}$ & 3 & 116 & 25 & 38 & 1.026 & 8 & 40 & 342 & & & 855 \\
\hline $\begin{array}{l}\text { ganado } \\
\text { (cabs.) }\end{array}$ & 51 & 535 & 556 & & 8.340 & 462 & & & 565 & & 10.735 \\
\hline $\begin{array}{l}\text { trigo } \\
\text { (fanegas) }\end{array}$ & 106 & 840 & 3.533 & 16 & 3.160 & 2536 & & & 25 & 28 & 718 \\
\hline $\begin{array}{l}\text { mal trigo } \\
\text { fans) }\end{array}$ & & & & & & 17 & 14 & 215 & & & \\
\hline $\begin{array}{l}\text { centeno } \\
\text { (fans.) }\end{array}$ & 56 & & 941,1 & & 10.529 & 902 & 10 & 9026 & 799 & 21 & 17.601 \\
\hline $\begin{array}{l}\text { cebada } \\
\text { fans.) }\end{array}$ & 51 & 827 & 1689,1 & & 15.251 & 1.368 & 8 & 11192 & 1036 & 18 & 15296 \\
\hline $\begin{array}{l}\text { avena } \\
\text { (fanegas) }\end{array}$ & 1,5 & 6 & 320,1 & & 1.608 & 102 & 6 & 528 & 269 & 9 & 2.391 \\
\hline $\begin{array}{l}\text { minucias } \\
\text { (reales) }\end{array}$ & 62 & & & 4672 & 340 & & & & & 769 \\
\hline $\begin{array}{l}\text { azafrán } \\
\text { (onzas) }\end{array}$ & & & & & 35.270 & & & 26921 & & & 54.672 \\
\hline $\begin{array}{l}\text { total } \\
\text { (rls.) }\end{array}$ & & 3315 & & & 19342 & & & 47.672 & & \\
\hline $\begin{array}{l}\text { data / } \\
\text { gastos }\end{array}$ & & & & & & & & & & & \\
\hline
\end{tabular}

\section{Elaboración propia. Fuente: ACM, Legajos, Cuentas de tazmías}

Pero, como en 1695, también en 1743, 1746 y 1750 se recolectó azafrán (en 1746 los contadores dispusieron que se entregase a Juan Alonso, vecino de Mahora), más abundante en Chinchilla que en Albacete y La Gineta, y se separó de la renta de minucias y se pasó al diezmo mayor en 1740, pero hasta 1754 no se pagó a los recogedores su sala- 
rio por ello, cuando el cabildo preguntó cuántos eran (ACM, 435/30, $575 / 29$ y $620 / 16,1754)$. Se recomendaron 2 días para los de Salobral, Villar, Corral Rubio y Albacete, 1,5 Pétrola, 3 Bonete, Casas sueltas, Gineta, Higueruela y Fuente Álamo y 4 Tinageros. Se constató el cultivo del azafrán en La Roda en 1755 (Escribano, 1984). A José del Rey Santa, de Higueruela, se le confiscaron 40 fanegas de azafranar (ACM, 364/16, 17.9-2.12.1735).

Cuadro 6. Diezmo del azafrán en Chinchilla, Albacete y La Gineta (1752-1753)

\begin{tabular}{|c|c|c|c|c|}
\hline 1752 & torrado & adobado & 1753 total & \\
\hline Chinchilla & 25,4 & 1,2 & 22 & \\
\hline El Villar & 1,14 & 0,1 & 1,1 & 0,13 \\
\hline El Salobral & 2,1 & 1,1 & 1,11 & 0,2 \\
\hline Higueruela & 3,14 & 1,1 & 3 & 0,12 \\
\hline Pétrola & 1,5 & 0,6 & 0,2 & 0,25 \\
\hline Fuente Álamo & 3,12 & & 2,4 & \\
\hline Bonete & 4,4 & 0,4 & 2,1 & \\
\hline Casas sueltas & 0,7 & & 1,12 & 0,2 \\
\hline Corral Rubio & 0,12 & & 0,8 & \\
\hline Albacete & 0,4 & & 0,6 & 0,2 \\
\hline & 31,4 & 3,8 & 19,6 & 1,15 \\
\hline Tinageros & & & 4,11 & \\
\hline Gineta & & & 1,4 & \\
\hline
\end{tabular}

Elaboración propia. Fuente: ACM, Legajos, Cuentas de tazmías

Una parte de los beneficios de los diezmos de Chinchilla revertió en la edificación de una nueva tercia en 1726-1732 (Cuentas de Antonio Núñez de Reina por Francisco Javier de Cantos: ACM, 364/14), a partir de caudales procedentes de las minucias de 1715 a 1735. Se llamó fincas a las deudas que dejaron arrendadores de minucias y uva.

Sin embargo, este crecimiento no se hizo sin problemas de insolvencia. El Tribunal de la Cruzada procesó y ejecutó a muchos por deudas (cuadro 3), a las que pudo contribuir una mayor fiscalidad, tanto en el repartimiento del subsidio y excusado sobre las rentas eclesiásticas (1728, cuadro 4), que administró la Junta de Gobierno y Administración del Excusado, lo que nos muestra un ejemplo de transferencia de dinero del perceptor eclesiástico al destinatario, es decir a las Galeras de España, como en otras rentas.

Veamos cómo se distribuía el diezmo por partícipes o perceptores: rey, obispo, cabildo: 


\section{Cuadro 7. Distribución del diezmo de Chinchilla entre sus partícipes}

(1716-1720)

\begin{tabular}{|l|l|l|l|l|l|l|l|l|}
\hline Producto & $\begin{array}{l}\text { rey } 6 \\
2 / 3\end{array}$ & parroquia 3 bo & obispo 3/5 & $\begin{array}{l}\text { cabildo } \\
2 / 35\end{array}$ & 6 beneficiado & tercería & S.Fulg.3 b. & presto \\
\hline lana prieta (@) & 126,16 & 57 & 33,19 & 162,13 & 114 & 19 & 57 & \\
\hline lana blanca (ídem) & 11,11 & 4,24 & 2,23 & 14,05 & 9,24 & 1,16 & 4,24 & \\
\hline ganado (cabezas) & 1392 & 627 & 373 & 1788 & 1254 & 209 & 627 & \\
\hline trigo (fanegas) & 6227,5 & 2802,03 & 1660,6 & 7991,07 & 5604,06 & 934,01 & 2446,1 & 355,04 \\
\hline mal trigo (ídem) & 646,25 & 290,09 & 172,03 & 829,02 & 581,06 & 96,11 & 253,25 & 37,08 \\
\hline centeno (ídem) & 3280 & 1476 & 874,08 & 4209,03 & 2952 & 492 & 1254,03 & 221,08 \\
\hline cebada (ídem) & 5015,06 & 2257 & 1337,05 & 6436,07 & 4514 & 752,04 & 1917,09 & 339,03 \\
\hline avena (ídem) & 411,01 & 185 & 109,07 & 527,07 & 370 & 61,08 & 164,1 & 20,1 \\
\hline total (fanegas) & 15579 & 7010 & 4152 & 19992 & 14071 & 2335 & 9451 & 1561 \\
\hline $\begin{array}{l}\text { data / gastos } \\
\text { recolección }\end{array}$ & 24473 & 11013 & 6526 & 31407 & 22026 & 3671 & 157 & \\
\hline
\end{tabular}

Elaboración propia. Fuente: ACM, Legajos, Cuentas de tazmías

Como puede apreciarse la parte que se llevó la parroquia fue pequeña en comparación a las del rey y los demás, con excepción del obispo y del Seminario de San Fulgencio.

\section{PROBLEMAS DE COLECTORES, FIELES, MAYORES HACENDADOS}

Los fieles colectores manifestaron su agradecimiento por su nombramiento, como Juan Martínez Gordo en Villamalea (ACM, 546/2, 17.1.1707), lo que indica que pudo ser lucrativo y quizá tuvo buena consideración. No obstante, los colectores y fieles tuvieron dificultades, tanto en 1709-1712, es decir, en la Guerra de Sucesión, como en 1716 y 1720-1721, por lo que procedieron contra deudores; o en 1742 con la recaudación de colmenas y cera en la aldea de Higueruela, pues algunos de sus moradores se resistieron a pagar el diezmo entero.

Los administradores generales tuvieron dificultades en plena Guerra de Sucesión de Polonia, en la que aumentó la fiscalidad y se llegó a la bancarrota de 1739 (Fernández, 1977; Dubet, 2017), con vecinos de Albacete y arrendadores de rentas de minucias y uva de heredades, que evitaron competidores valiéndose de personas de autoridad y de favores disuasorios.

Se sumaron dificultades procedimentales, como la revisión de cuentas de 1721 sobre los 5 años anteriores, por la que consta corresponder al rey 6 beneficios y $2 / 3$ de otro, a la parroquia 3 beneficios, al obispo $1 / 3$ de 5 beneficios, $1 / 3$ de 8 en parte de las tercias, al cabildo $2 / 3$ de 5 beneficios y $1 / 3$ de otro del obispo. Hubo una tercería de 
Chinchilla (un beneficio suelto de turno entre 6), y a los 3 beneficios del Seminario de San Fulgencio se descontó el prestamillo o beneficio préstamo (ACM, 365/21, 1721).

Fue más importante el resurgimiento de la reclamación de 1697 por labradores y ganaderos de Chinchilla contra arrendadores y recaudadores decimales por prohibirles pujar a las ventas de ganados que les cobraron, que ejercieron pero que renunciaron, como en 1739 labradores de Hellín protestaron contra los asentistas de las minas de azufre, por el abuso de cobrarles un canon de 3 sobre 10 (Rodríguez, 1984; el diezmo fue 1/10). Los recaudadores beneficiaron a vecinos de Caudete (Azorín, 2008).

En la Guerra de Sucesión de Austria, en la que Felipe V intentó conquistar la Toscana, consiguió cargar al clero un subsidio extraordinario más, del 8\% de sus rentas, pero su recaudación se demoró a 1744-1746, es decir, al final de su reinado, que fue conflictivo en las relaciones con Roma, pues el papa Clemente XI aceptó al archiduque Carlos de Austria como sucesor del reino de España y sólo se llegó a un acuerdo en 1737 (Aldea, 1977). Por ello se alargó la tramitación y dio lugar a que algunos presbíteros muriesen y el administrador Pablo Núñez Flores reclamase a sus herederos, como los de Ramiro Antonio Barnuevo (ACM, 524/10, 1744 y 1745).

\section{EVOLUCIÓN DE LA ADMINISTRACIÓN DEL DIEZMO EN 1751- 1800}

\subsection{Evolución y problemática general}

En 1751-1800 la producción agraria (cuadro 8/9) fue sometida a grandes anomalías físicas como el Terremoto de Lisboa (1755), en que creció el agua de fuentes en Peñas o agua de pilas en Chinchilla (Rodríguez, 1981, p. 95), o a otras políticas, como la libertad de precios en 1765 (Castro, 1989) y nuevos impuestos.

Cuadro 8. Evolución del precio del diezmo de Chinchilla en 1750-1799

\begin{tabular}{|c|c|c|c|c|c|c|c|c|c|c|c|c|}
\hline CHINCHILLA & 1750 & 1754 & 1755 & 1759 & 1760 & 1761 & 1763 & 1766 & 1767 & 1769 & 1771 & 1772 \\
\hline Lana prieta & 30 & 40 & 45 & 46 & 46 & 40 & 40 & 33 & 37 & 40 & 41 & 42 \\
\hline Lana blanca & & 55 & 55 & 56 & 56 & 48 & 50 & 43 & 47 & 50 & 51 & 52 \\
\hline Ganado & & 26 & 30 & 20,5 & & 23,5 & 26 & 21 & 25 & 24 & 28 & 28 \\
\hline Trigo bueno & 28 & & & & & & 34 & & & & & 41 \\
\hline Trigo jeja & & 20 & 17 & & & & 30 & & & 34 & & 46 \\
\hline
\end{tabular}




\begin{tabular}{|c|c|c|c|c|c|c|c|c|c|c|c|c|}
\hline Jeja imperf & 21 & 14 & & & 15 & 14 & & 33 & & & & 29 \\
\hline Centeno & 18 & 16 & 11,5 & 12,5 & & 7,5 & 20 & 20 & & & & 20 \\
\hline Cebada & 9 & 10 & 12 & 10 & 6 & 4,5 & 15 & & & 10 & 6 & 12,5 \\
\hline Avena & & & 6 & 6 & & & 8 & & 10 & & & \\
\hline Minucias uva & & & & & 59 & & & 10 & & & & \\
\hline Azafrán loa & 1773 & 1775 & 1776 & 1781 & 1783 & 1786 & 1788 & 1790 & 1799 & & & \\
\hline $\begin{array}{c}\text { Trigo mo- } \\
\text { jado }\end{array}$ & 40 & 40 & 40,5 & 41 & 50 & 48 & 45 & 42 & 56 & & & \\
\hline Lana prieta & 50 & 50 & 50 & 50 & 60 & 58 & 55 & 52 & 66 & & & \\
\hline Lana blanca & 24 & 24 & 24 & 30 & 33,5 & 18 & 26 & 21,25 & 33 & & & \\
\hline Ganado & 45 & & 32 & & & & & & & & & \\
\hline Trigo bueno & 37,5 & & 25,5 & & & & & & & & & \\
\hline Trigo jeja & $31-4$ & & 24 & & & & & & & & & \\
\hline $\begin{array}{l}\text { Jeja imper- } \\
\text { fecto }\end{array}$ & 24 & & 19 & & & & & & & & & \\
\hline Centeno & 17 & & 12 & & & & & & 14 & & & \\
\hline Cebada & 9 & 7 & 6 & 4 & 6 & 12 & & & & & & \\
\hline
\end{tabular}

Elaboración propia. Fuente: ACM, Legajos, Cuentas de tazmías

Los precios de la lana blanca subieron de 50 a 66 reales de 1761 a 1799 y de la lana prieta de 40 a 56, con una puntual bajada en 1767; el ganado de 22 a 30 (hasta 1781), el trigo de 25 a 40, pero sólo entre 1761 y 1767; el centeno de 14 a 26 (hasta 1767), la cebada de 8 a 20 (igual), la avena de 5 a 15 (hasta 1784) y las minucias de 570 en 1761 a 17.807 reales en 1798, lo que muestra un decaimiento a partir de 1767 o 1784.

Se hicieron obras en las casas pilas y tercias de la Felipa y La Gineta, lo que indica bonanza, pero hubo endeudamientos de arrendadores de minucias y uva, y epidemias de langosta (1757-1759), por lo que los vecinos de Albacete pagaron 14.588 reales de décima, que primero fueron 4.160,18, 3.000 y 1.918 (ACM, 442/22, 1765).

En cuanto a la producción a través de este indicador la lana prieta se elevó de 2.395 arrobas (1753) a 3.950 y 4.312 (1788 y 1799), la lana blanca de 428 a 813, o la avena de 3434 fanegas (1753) a 16399 (1790), es decir, se duplicaron o más, mientras que trigo, centeno y cebada no tuvieron tales incrementos, pero sí las minucias y uva: de 7.700 reales (1753) a 11001 (1788). Hubo diversas crisis en 1763, 1766,1771 y 1777.

Calero, sucesor de Pablo Núñez Flores, afrontó otro problema, el de la adjudicación de la conducción de los diezmos, pues los transpor- 


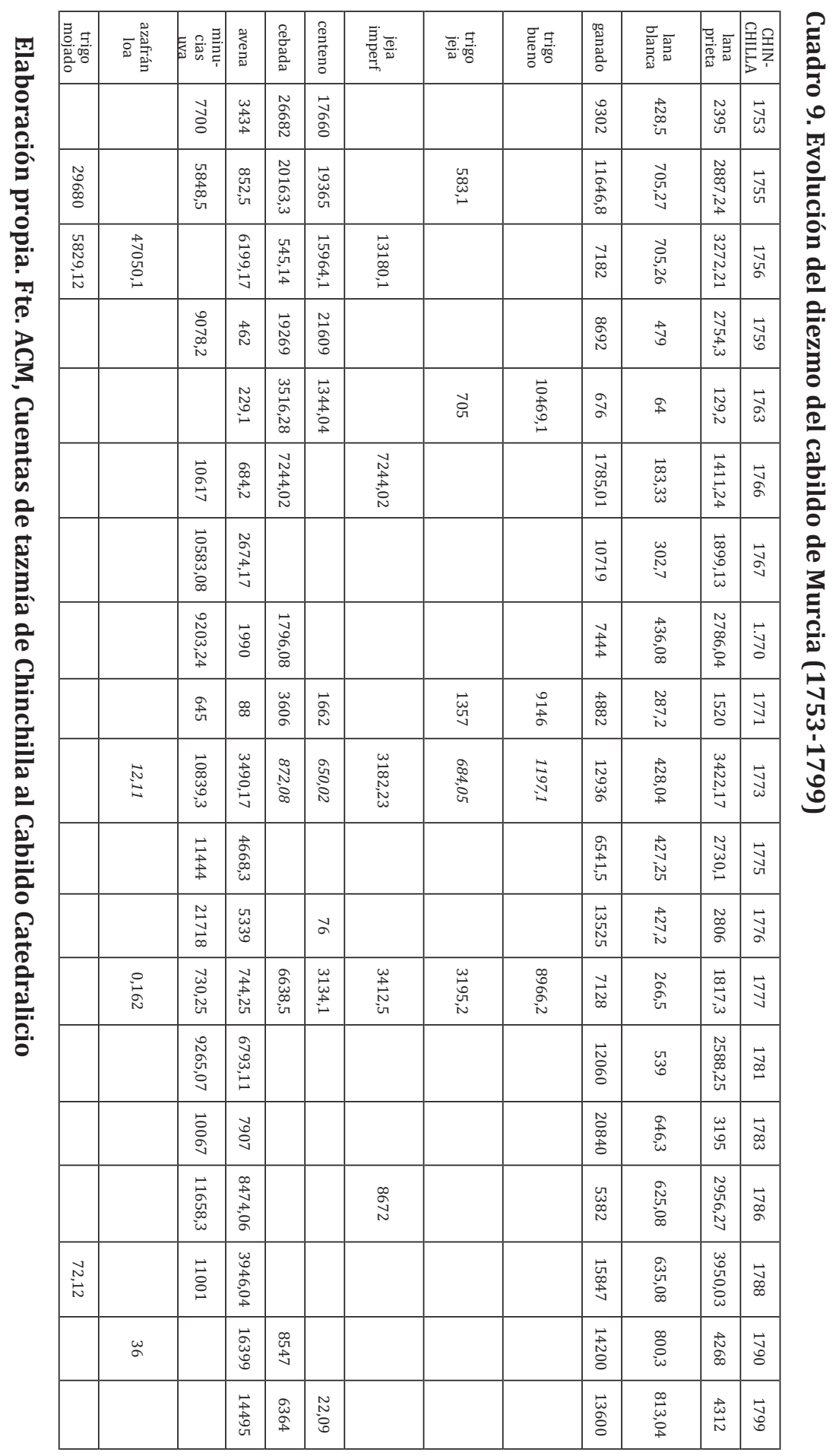


tistas se molestaron entre ellos, por pasión, atropellándose y ofreciendo precios que no cumplieron, por lo que los fieles mayores la adjudicaron directamente, pero el cabildo previno de no estancarla en unos mismos (ACM, 628/32, 27 y 30.6.1772). Se deduce de las hipotecas de sus fiadores que el viñedo ganó terreno, como en Yecla, sin llegar a desbancar al cereal (cuadro 10).

Cuadro 10. Fianzas de los fiadores del colector Antonio Calero

\begin{tabular}{|l|l|l|l|l|l|l|}
\hline Fiadores & Total: 116.400 rls. & cereal & Rls. & vides & rls. & $\begin{array}{l}\text { casa/ } \\
\text { rl. }\end{array}$ \\
\hline Manuel Cano & Higueruela & casa y 177 almudes cereal & 37200 & 3500 & 6300 & 3000 \\
\hline Blas Colmenero & Higueruela & $\begin{array}{l}30,5 \text { almudes cebadal/ } \\
\text { trigal }\end{array}$ & 16700 & 3000 & 6000 & 9000 \\
\hline $\begin{array}{l}\text { Jerónimo Ba- } \\
\text { llestero Peral }\end{array}$ & Higueruela & $\begin{array}{l}33 \text { almudes cebadal y } \\
\text { trigal }\end{array}$ & 10000 & 4000 & 10000 & 7000 \\
\hline José Verdejo & Higueruela & $\begin{array}{l}5 \text { hazas: } 3+\text { almudes ce- } \\
\text { badal }\end{array}$ & 6600 & 8000 & 6600 & 7000 \\
\hline
\end{tabular}

Elaboración propia. Fuente: ACM, Legajos, 549/36, 1772.

Hubo otras circunstancias adversas: el pedrisco, como en el de Baltasar del Rey, arrendador de las minucias de uva de Chinchilla: El 12.12.1772 el cabildo decidió darle de plazo hasta agosto de 1773, por lo que se le dio moratoria, y en 1775 el capellán de la de Gaspar Ballestero declaró que las viñas habían decaído mucho por su naturaleza, hielos, plagas de gusanos y escarabajos, pero se introdujo otra (ACM, $628 / 32$ y 558/6, 13.7.1775), que el último declaró para justificar sus ingresos.

\subsection{Libertad de precios de 1765 en adelante}

El administrador del excusado, como se hizo siempre, observó una variación anómala de los precios de los granos: "pero la cebada se ha puesto hoy a 28 reales, esto se entiende los cosecheros que son los que únicamente y por necesidad venden algunas fanegas", y algo parecido sucedió después: bajó la cebada a 30 reales (ACM, 575/29, 14.3, 18.4, $2.5,2.6 .1798)$, lo que se puede entender en el contexto de la libertad de precios que el gobierno promulgó en 1765 y repercutió en el motín de Esquilache, que llevó a que los cosecheros especulasen con los precios y esperaron a vender cuando fuesen más elevados.

Pasados diez años de la instauración de libertad, de precios Francisco Valera denunció la dificultad de vender los frutos o granos por falta de compradores, pues iban a La Mancha a comprarlos me- 
jores y más baratos. Además hubo labradores de Albacete que dejaron de pagar el diezmo a los fieles de Chinchilla y lo hicieron al fiel cuarentín de Albacete, con quien disputaron aquéllos, por lo que se hizo un apeo o deslinde entre ellas y La Gineta (Imagen p. 82). A él asistieron de Chinchilla Joaquín Aguado Torremocha, corregidor, Jerónimo Núñez Robres, alguacil mayor, Pedro Maza de Lizana, Vicente Isidoro Cano Manuel, Marcos Marín Cantos, Salvador María Barnuevo Sandoval, teniente coronel, Pedro de la Mota Moreno y Tomás Pablo Galiano, regidores, y Rodrigo Muñoz de Lara, procurador síndico; de Albacete Felipe Antonio de Zamora, teniente de corregidor, Francisco de Alfaro Morales, Gil Fernández Cortés, Ginés de Cantos Carrasco, regidores; y de La Gineta Jorge Navarro, alcalde ordinario, Francisco Fernández Carcelén, Martín Garrido y Francisco Saavedra, regidores, y Juan García Armero, procurador síndico (ACM, 594/1, 1778; sobre Cantos: Cózar, 2008, p. 56). En él se refleja desde La Roda hasta Pétrola, pasando por La Gineta, Albacete y Chinchilla, más los mojones del camino murciano, Algibe de los bestiares, el Villarejo, Santa Cruz, huerta de Lázaro Martínez, Cuerda de la Costera y la Saeta; mojones del lado de Barrax: la Losa Llana, Cañada de los Pastores, Nava de Acequión, el Villarejo, entino de la Atalaya de San Jorge, entino opuesto de la huerta de Lázaro Martínez, cerrillo cabo el Regajo y las Encebras cerca de Meledriz, y del lado del río: el Escalón, el Camino Bado de la Marmota, hoyuela encima de la Marmota, cimiento del cabo del Villar de Asensio, corral cerca del camino de los carruajes, cerrillo entino y siesto de la losa la Cogullana, casas de Juan Sánchez, cerca la casa de D. Álvaro Farri o Malpelo.

Vecinos de La Roda compraron cereales a la tercia del rey y los vendieron más baratos: "sin embargo de dichos precios se despachan muy pocos frutos por falta de compradores, que se pasan a La Mancha a hacer su empleo por encontrarlos allí de mejor calidad y más conveniencia" (ACM, 528/2, 21.11.1775- 23.11.1776; 392/13, 17.84.9.1776: Cuarto Alfaro o Casa Jimena). Surgió por tanto una mayor competencia.

La liberalización de precios coincidió con años de malas cosechas (Losa, 1984, 131), por lo que las dificultades de abastecimiento se hicieron mayores.

\subsection{Los grandes hacendados, mayores contribuyentes dezmeros}

Hubo problemas con los grandes hacendados (cuadro 11): los fieles mayores de Chinchilla Núñez Flores, José Agustín Durbán y Julián López de Arrieta informaron de que sus tercias se unían en común acervo o cilla a las de las parroquias de la ciudad y lugares de Higuerue- 
la, Bonete, Pétrola y el Villar, aunque cada una tenía territorio particular y parroquianos distintos, y se reconvino (despacho de 18.9.1770) a Antonio López de Haro, dezmante excusado de Chinchilla, Juan Royo Gabaldón de Higueruela (posiblemente autor del memorial de Hellín mencionado por Rodríguez, 1984, p. 194), Fernando Vicente Pérez Pastor de Pétrola, Salvador María de Barnuevo de Bonete y éste por tutor de los herederos de Sancho Ramiro Barnuevo y Felipa Abat Ortega, del Villar, los últimos feligreses de Chinchilla, para cumplir los capítulos de la real instrucción y sobre declaración de dudas en real decreto de 14.1.1762 de administración y exacción de frutos excusados. Según éste debían pagar los diezmos que adeudasen fuera de su territorio propio y privativo en la tercia de su vecindad. Barnuevo contestó que seguiría pagando a Martín Soriano, administrador general de la gracia del excusado, a quien dio el diezmo de lana y ganado (ACM, 555/18, 10.8.1771).

Cuadro 11. Grandes hacendados de Chinchilla (1763-1790)

\begin{tabular}{|c|c|c|}
\hline Grandes hacendados Chinchilla & Años & Población \\
\hline Pedro Núñez Flores & 1763 & \\
\hline Salvador Barnuevo & $1771-1776$ & Higueruela \\
\hline Fernando Núñez de Robres & $1771-1776$ & Bonete \\
\hline Juan de Cañas & $1771-1776$ & Bonete \\
\hline Fernando Vicente Pérez Pastor & $1771-1776$ & Pétrola \\
\hline Sancho Barnuevo & $1771-1776$ & Villar \\
\hline Juan López Royo & $1771-1776$ & Casas de Royo \\
\hline Antonio López de Haro & 1776 & \\
\hline Diego Núñez Robres & 1776 & \\
\hline José López de Haro regidor & 1790 & \\
\hline
\end{tabular}

Elaboración propia. Fuente: ACM, Legajos 528/2, 1775-77; 737/11, 1790

Tal problema muestra quiénes eran los grandes hacendados en 1771 y que algunos eran absentistas, como más adelante Jerónimo Núñez Robres, natural de Chinchilla, que se llevó su ganado, nombrado corregidor de Hellín, lo que no dejaron pasar los fieles dezmeros de Chinchilla, que reclamaron los diezmos de carne y lana, pero los fieles de Hellín defendieron su derecho al diezmo, que apoyó el cabildo (ACM, 743/3, 1788-89).

Por lo tanto fueron mayores hacendados los grandes propietarios de Chinchilla, como es lógico, pues eran los mayores productores (so- 
bre Barnuevo: Muñoz, 2010, pp. 333-334; Cózar, 2014, p. 186), al mismo tiempo que eran regidores de su concejo o cabildo.

Pero el administrador Francisco Valera, arcipreste y colector de perpetuales, sugirió a la Junta de la Real Gracia del Excusado cambios:

Cuadro 12. Cambios de los hacendados de 5 ${ }^{\mathbf{a}}$ casa excusada

\begin{tabular}{|c|c|c|}
\hline Hacendado 5a casa excusada & Nuevo hacendado & Población \\
\hline Antonio López de Haro+ & Diego Núñez Robles & Chinchilla \\
\hline Juan Royo & Salvador María Barnuevo & $\begin{array}{c}\text { Higueruela } \\
\text { (Heredad Vete) }\end{array}$ \\
\hline Fernando Pérez Pastor & Ídem & Pétrola \\
\hline menores de Sancho Barnuevo & Ídem & El Villar \\
\hline Juan de Cañas & Ídem & $\begin{array}{c}\text { Bonete: may } \\
\text { Corral Rubio }\end{array}$ \\
\hline
\end{tabular}

Elaboración propia. Fuente: ACM, 528/1, 1773

En 1777 las cifras de las cuentas de la mesa capitular de la 5a casa, de Tomás Carbonell, administrador de Juan de Cañas (ACM, 769/29), fueron más elevadas. Las rentas de minucias se desglosaron más, indicando la capacidad de actuación del administrador con los grandes hacendados, a quienes pidió relaciones juradas e hizo asientos con ellos:

\section{Cuadro 13. Arrendadores de uva de Chinchilla en 1777}

\begin{tabular}{|c|c|}
\hline Persona & Población \\
\hline José del Rey Santa & Higueruela \\
\hline Nicolás Martínez Salcedo & Bonete \\
\hline Jacinto Alcázar Martínez & El Salobral \\
\hline Ramón Moreno & Pétrola \\
\hline Blas Martínez Dompedro & ejido Chinchilla \\
\hline
\end{tabular}

Elaboración propia. Fuente: ACM, Legajos, 397/31

Manuel Robles, capellán regio de las Calatravas de Madrid, negó pagar diezmo de su ganado por ser caballero de Calatrava. Vicente Isidro Cano Manuel, mayordomo de la fábrica parroquial, tuvo de renta 3 de 30 partes de los diezmos (en 1773-1777 ingresos de 315.440 y gastos de $282.117=33.323$ ) y un censo de 131 reales 28 mrs., y gastos de alimentos a iglesias filiales, salarios de curas y sacristanes y sueldos de ministriles (ACM, 543/12, 7.8.1781).

Hubo aún mayores dificultades en la recolección: Vicente Cano Manuel se negó a pagar el diezmo de sus primales si se le cobraba en 
Madrid, pues no debía pagar diezmo 2 veces (ACM, 737/5, 26.6, 4, 7, 11.8.1790, 9 y 19.1.1791), y algunos arrendadores de uva abusaron en retrasar el pago de la renta al vender vino al por menor (debían 21.824 reales de 1795 los de Chinchilla, Higueruela, Bonete, Fuente Álamo, El Villar y Pozo Cañada), que prohibió el corregidor José María de Yanguas y Acuña, quien además exigió se le pidiera permiso para poner papeletas de subastas de rentas:

"dichos arrendadores no pagan sus rentas, diciendo no pueden hacerlo sin vender el fruto y las que han rematado las de el presente año se niegan a otorgar las correspondientes escrituras", "y si en tiempo hubieran acudido como los demás vecinos a manifestar las producciones del diezmo acaso tuvieran el mismo permiso, pues una de las causas que alega el corregidor para la prohibición [fue verbal] es no haber aforado sus bodegas como todos los vecinos, y con el nombre de vino de diezmos introducir el comprado de cosecheros para que goce el mismo indulto fuera que éste es uno de los casos fortuitos que renunciaron los arrendadores en sus escrituras... Más repulsa merecen los que remataron el presente año los diezmos de uva, pues sabían muy bien la prohibición publicada de vender el vino por menor cuando los arrendaron, en cuya inteligencia hicieron las posturas y se celebraron los remates, por lo cual se les debe precisar a que celebren escrituras con hipotecas" (Los fieles de Chinchilla a los contadores de Murcia y al revés: ACM, 642/26, 2, 15, 27.8 y 5.9.1795; y 642/28, 7, 15, 18, 28.7, 1.8.1795-20.12.1796).

Se dio así un pequeño conflicto entonces muy corriente entre jurisdicción civil y eclesiástica.

\subsection{Pervivencia de la ganadería}

En estos años se puede comprobar la presión de vecinos de Alcalá del Río Júcar (1767), Jorquera (1771), Casas de Juan Núñez (1773), Ayora y Jalance (1769) (estos dos últimos valencianos) para comprar ganado y lana dezmeña, según extracto remitido a los fieles removidos de Chinchilla, lo que indica que la ganadería creció, como en Yecla en estos años (Carpena, 2019, 30-31). El ganado decimal se vendió a vecinos de Ayora, Enguera y Jalance (Valencia), como Agustín Verdejo (Cuentas de la mesa de 1766 y 1770: ACM, 446/12 y 448/13). En Chinchilla concurría la cabaña y cañada ganadera de Cuenca, que desde aquella se internaba en el Reino de Murcia, o anteriormente en el Partido de Alcaraz de la Provincia de La Mancha creada en 1718 (Rodríguez, 2014, p. 93), de aquí que abundara el ganado, que aumentó con el ganado local. 


\subsection{Nombramientos de fieles andadores y cuarentines}

Cuando cesó el marqués de la Ensenada (1754), a pesar de que se continuó con el catastro de su nombre, los fieles José de Cantos, Miguel Antonio Molina y Fernando Molina propusieron como fiel andador a Esteban Escobar, por dimisión de Mateo Alcázar, pero el cabildo les pidió que presentasen a tres candidatos y Escobar fue nombrado fiel interino en La Gineta, que pidió Lencina (ACM, 575/55 y 84, 23.7, 13.8.1754, 20.6, 6, 8.7.1755), lo que muestra el celo del cabildo por sus prerrogativas.

El nombramiento de fieles andadores y cuarentines fue delicado, pues algunos de estos últimos fueron acusados de mala conducta por extraviar diezmos y el cabildo se quejó de la desidia de los colectores (Imagen p. 83) (ACM, 543/13, 1772, 28.9.1780, 1782).

Además, el cabildo catedralicio hubo de afrontar las peticiones de los fieles cuarentines de Bonete y Fuente Álamo: el primero (José Burgos) consiguió que se le aumentase su salario en 70 reales, pero el segundo (Gregorio Hortelano) no obtuvo traslado al Salobral, pues si previamente sí lo hizo interinamente se retiró de él al negarse los comisarios del Hospicio de San Pedro de Los Llanos o de Nuestra Señora de las Nieves a que almacenase allí y los fieles terceros le acusaron de cobardía. Además, Vicente Rodino, alguacil mayor de Albacete, pidió al cuarentín de la tercia 72 reales de utensilios, servicios y olmos de mano muerta, y los fieles insistieron en el cobro del diezmo de salicor a Pascual Tortosa y Manuel de Cañas y el de aceite de Fuente Álamo. Salicor y aceite se pasó a cobrar 1/10-1/14 y 1/12 arrobas (ACM, 642/26, $30.1,13.2,8.3,25.6,2,5$ y 9.7, 14/17.9.1796, 13.5.1797).

\subsection{Subsidio y excusado}

Cristóbal Herreros, cura párroco de Santa María de Chinchilla, tuvo los ingresos y gastos siguientes de subsidio y excusado:

Cuadro 14. Cuentas de subsidio y excusado de Chinchilla en 1779

\begin{tabular}{|c|c|c|c|}
\hline Ingresos & Rls. & Gastos & rls. \\
\hline $\begin{array}{l}\text { Primicias (diezmo de frutos prime- } \\
\text { ros de la cosecha) }\end{array}$ & 9300 & $\begin{array}{l}\text { Recolección primi- } \\
\text { cias }\end{array}$ & 700 \\
\hline Otro ingreso & 3300 & subsidio-excusado & 160 \\
\hline $\begin{array}{l}\text { patronato Hospital, montes píos y } \\
\text { capellanía Gaspar Páez }\end{array}$ & 302 & salario 2 tenientes & 2000 \\
\hline
\end{tabular}




\begin{tabular}{|c|c|c|c|}
\hline total & 12902 & Cofradía N.P.Jesús & escote \\
\hline 6 beneficios y 3 pascuales & 3090 & Cofradía N.S. Dolores & escote \\
\hline asistencia al coro & 1100 & Cofradía Fuensanta & escote \\
\hline & & $\begin{array}{c}\text { Cofradía S.Pedroo / } \\
\text { Pablō }\end{array}$ & escote \\
\hline & & Cofradía N.S.Carmen & escote \\
\hline & & Cofradía S. Ildefonso & escote \\
\hline & & Cofradía S. Sebastián & escote \\
\hline & & Cofradía San Julián & escote \\
\hline & & Cofradía San José & escote \\
\hline & & Cofradía San Blas & escote \\
\hline & & Cofradía San Roque & escote \\
\hline & & Cofradía San Vicente & escote \\
\hline & & Cofradía Santa Lucía & escote \\
\hline & & Cofradías Ánimas (2) & escote \\
\hline & & Ermita N.S.Fuensanta & 55 \\
\hline
\end{tabular}

Elaboración propia. Fuente: ACM, Legajos, 553/3

Como se ve, las cofradías no aportaban al subsidio y excusado, por no tener rentas ni propiedades, pero sí la Ermita de la Fuensanta para alumbrar una lámpara de aceite.

En su selección los contadores del cabildo entablaron un pleito en 1782, para el que fue comisionado Miguel Dionisio Sotos según oficio de Ramón García Abellán (ACM, 543/13, Chinchilla, 27.6.1782).

La administración de las rentas arrendables (minucias, uva) correspondió al fiel tercero que nombró el obispo y en 1787 se demoró en pagar a los partícipes beneficiarios de los diezmos, lo que provocó reclamaciones de Mateo Alcázar Escobar y otros problemas: en 1782 con la recaudación de colmenas y cera en la aldea de Higueruela, pues algunos de sus moradores se resistieron a pagar el diezmo entero, e incluso trasladaron sus colmenas al arzobispado de Valencia para evitar su pago entero, o en 1789 con un rentero, Simón García, de Chinchilla, por 3729 reales de minucias (ACM, 737/7, 11, 23.10, 18.12.1790).

Por ejemplo, Pedro de la Mota Moreno, regidor de Chinchilla, pidió cuenta del diezmo que pagó su madre (Josefa Moreno Benítez) de 1773 
a 1779, pues entonces ella le hizo un préstamo de 8.000 reales, para lo que le cedió la renta de parte de un vínculo en el heredamiento de Aldeanueva y falleció sin dar cuenta de aquélla, por lo que se destituyó al fiel tercero Miguel Merino (ACM, 772/6 2,5, 16.6, 4, 11, 25 y 26.7 y 28.11.1787; sobre Moreno Benítez: AHPAl, Not. 681/2/31, 24.5.1715; Feliciano fue regidor desde 1686: Molina, 2007a, 71).

Los gastos o data de las rentas arrendables o minucias y uva se destinaron al cura de Bonete para una pía memoria de la casa pila de Corral Rubio (10,26 reales), al mismo para la procesión de rogativa del día de San Bernabé (30), los comisarios y clero de la ciudad por la rogativa de Nuestra Señora de las Nieves (120) y 8 pastores que guardaron el ganado del diezmo (283) en 1781.

José Colmenero (ACM, 545/26), y Ramón García Abellán, presbítero de La Higueruela, como nuevo colector y administrador de Chinchilla, por 70.000 reales, tras renuncia del arcipreste Francisco Valera, extendieron hipoteca por el subcolector del subsidio eclesiástico en 1799 a la casa nueva de Chinchilla y a la escritura de fianza (ACM, 547/47, 7.10.1799).

\subsection{Nuevas contribuciones de finales del siglo XVIII}

Se sumó entonces la contribución al Fondo Pío Beneficial, con motivo de la Guerra de Inglaterra de 1797-1802, de una décima parte de 2 beneficios y el prestamillo. En 1797 dieron 7.880 reales los 2 beneficios pensionados y el prestamillo y en 1802 se dotaron las vicarías perpetuas de Fuente Álamo y Pozo Cañada (ACM, 591/12, 1797-1798, 1802).

\section{CONCLUSIONES}

Se presentan en este texto los resultados de una investigación de la evolución social y económica de las poblaciones de Chinchilla de Montearagón y su corregimiento o distrito en los siglos XVII y XVIII, a través principalmente de dos fuentes: la documentación del cabildo catedralicio de Murcia y algunos protocolos notariales de Chinchilla conservados en el Archivo Histórico Provincial de Albacete.

En ambos fondos archivísticos se ha podido constatar la importancia de la gestión y administración del diezmo eclesiástico, tanto por la variedad de participantes: desde los grandes terratenientes (caballeros e hidalgos generalmente, seleccionados además como hacendados mayores) a los medianos y pequeños propietarios, ya como contribuyentes, arrendadores, fieles cuarentines o transportistas, como por las relaciones que trenzó entre las tercias decimales o los concejos y el 
cabildo catedralicio, o entre los propios concejos y tercias decimales, a veces tensas y encaminadas a exenciones o separaciones.

La trayectoria de la cuantía y valor del diezmo estuvo sometida a circunstancias políticas, como la liberalización de los precios de cereales por Carlos III (se suprimió la tasa sobre su precio de venta), la introducción o difusión de cultivos comerciales, como azafrán, cáñamo o vino, o la reducción del porcentaje de los réditos de los censos, aparte de las circunstancias climatológicas o tectónicas.

En la gestión de la recaudación del diezmo entraron administradores y colectores de distintos partícipes de sus beneficios: no sólo los del cabildo catedralicio, sino también los del obispo, los de las parroquias o sus fábricas y los del rey, además de los contribuyentes con sus intereses de exención y absentismo, o los de los arrendadores por conseguir beneficios; lo que dio lugar a muy numerosos conflictos. Estos últimos revelan tendencias de grupos y territorios, entre grandes y medianos o pequeños cosecheros, de ganaderos por aprovechar la movilidad de sus ganados para pagar menos, la de foráneos por adquirir ganado, o la de fieles cuarentines por mejorar su situación laboral, e incluso la pugna entre Chinchilla y Albacete por delimitar mejor su territorio.

En el proceso de la cobranza del diezmo entraron los llamados fieles andadores y cuarentines, ejecutores materiales de la actuación, por lo que fueron objeto de atención y tensión por parte de colectores y el cabildo, puesto que de ellos dependió la integridad de la recolección y la amplitud de los beneficios, fuente de intereses contrapuestos.

Finalmente otra aportación es un mejor conocimiento de la sociedad de Chinchilla y de otras poblaciones de su distrito en su conjunto y no sólo parcialmente, pues en torno a la cosecha y al diezmo giró toda la sociedad: el clero como perceptor y los pecheros y los nobles como contribuyentes. 


\section{REFERENCIAS BIBLIOGRÁFICAS}

ALDEA VAQUERO, Q. (1977). Historiografía concordataria española. En Primeras Jornadas de Bibliografía (pp. 97-108). Madrid: Fundación Universitaria Española.

ÁLVAREZ NOGAL, C. (1999). El factor general del rey y las finanzas de la Monarquía Hispánica, Revista de Historia Económica. (XVII-3), 507-539.

AZORÍN ABELLÁN, J. (2008). Entre la nostalgia y la realidad de una identidad rota. Caudete tras la Guerra de Sucesión. Albacete: Diputación Provincial de Albacete.

BELMONTE RUBIO, J. (2018). La canonjía doctoral en el Cabildo Catedral de Murcia. Murcia: El Autor.

BRINGAS GUTIÉRREZ, M.Á. (2012). La productividad de la tierra en la Corona de Castilla a mediados del siglo XVIII. En M.J. Pérez Álvarez, A. Martín García (Coords.), Campo y campesinos en la España moderna (pp. 945-956). Madrid: FEHM.

CÁNOVAS BOTÍA, A. (1994). Auge y decadencia de una institución eclesial: el Cabildo Catedral de Murcia en el siglo XVIII. Murcia: Universidad de Murcia.

CARPENA CHINCHILLA, F.J. (2019). Una suma de voluntades. La construcción de la Basílica de la Purísima de Yecla (1772-1868). Murcia: CEL Yecla.

CASTRO, C. (1989). La liberalización del comercio de granos y el abastecimiento de Madrid. En Estructuras agrarias y reformismo ilustrado en la España del siglo XVIII (p. 737-750). Madrid: Ministerio de Agricultura, Alimentación y Medio Ambiente.

CEBRIÁN ABELLÁN, A. (2019). Socioeconomía del señorío del Conde de Navas de Amores (Cinco Villas de Alcaraz, Albacete), según el Catastro de Ensenada, Murgetana Revista de la Real Academia Alfonso X el Sabio. (141), 37-62.

CÓZAR GUTIÉRREZ, R. (2008). Poder e historia local. Notas sobre las oligarquías de la villa de Albacete durante la Edad Moderna, Ensayos. (31), 33-63.

CÓZAR GUTIÉRREZ, R. (2014). La 'élite' de las élites de La Mancha oriental durante la Edad Moderna a través de las concesiones de hábitos de órdenes militares, Obradoiro de Historia Moderna. (23), 185-216.

DOMÍNGUEZ ORTIZ, A. (1985). Las clases privilegiadas del Antiguo Régimen. Madrid: Istmo.

DUBET, A. (2017). José Campillo y las secuelas de la suspensión de 
1739, Cuadernos de Historia Moderna. (42/2), 629-652.

EIRAS ROEL, A. (Coord.). (1984). La documentación notarial y la historia. Actas del II Coloquio de Metodología Histórica Aplicada. Santiago de Compostela: Universidad de Santiago de Compostela.

ESCRIBANO MARTÍNEZ, C. (1984). La agricultura en La Roda en el siglo XVIII. En A. Santamaría Conde, L.G. García-Saúco Beléndez (Coords.), Congreso de Historia de Albacete. Vol. 3 (pp. 245-254). Albacete: Instituto de Estudios Albacetenses Don Juan Manuel.

FERNÁNDEZ ALBALADEJO, P. (1977). El decreto de suspensión de pagos de 1739: análisis e implicaciones, Crédito y Moneda. (141), 52-71.

GANDÍA CUTILLAS, E. (2018). Entre Fronteras: Jumilla en la Edad Media. Murcia: Asamblea Regional, Real Academia Alfonso X el Sabio.

GARCÍA DÍAZ, I. (1988). La renta eclesiástica en Chinchilla en el siglo XV. I Congreso de Historia de Castilla La Mancha. T. 6 (pp. 47-51). Toledo: Junta de Comunidades de Castilla La Mancha.

GARCÍA DIAZ, I. (2014). El origen del Archivo de la Catedral de Murcia: el inventario de 1536, Historia, Instituciones, Documentos. (41), 205-242.

GARCÍA OLMO, M.A./IRIGOYEN LÓPEZ, A./GARCÍA HOURCADE, J.J. (2002). Albacete en los documentos episcopales durante la Edad Moderna. En A. Santamaría Conde, L.G. García-Saúco Beléndez (Coords.). II Congreso de Historia de Albacete. Vol. 3 (pp. 217-225). Albacete: Instituto de Estudios Albacetenses Don Juan Manuel.

IRIGOYEN LÓPEZ, A. (2001). Entre el cielo y la tierra, entre la familia y la institución. El Cabildo de la Catedral de Murcia en el siglo XVII. Murcia, Universidad de Murcia.

JUAN VIDAL, J. (1989). Los diezmos en la diócesis de Mallorca en el siglo XVI. Mayurqa Revista del Departament de Ciències Històriques i Teoria. (22/2), 811-824.

LACY PÉREZ DE LOS COBOS, S.M. (2002). Padrón de hidalgos en Chinchilla de Montearagón, Hidalguía. (292-293), 387-394.

LEMEUNIER, G. (1994). El régimen señorial en cuestión. De los enfrentamientos antiguos a la lucha por la tierra en los señoríos del Reino de Murcia (siglos XVI-XVIII), Murgetana Revista de la Real Academia Alfonso X el Sabio. (88), pp. 25-52.

LODOLINI, E. (1993). Archivística. Principios y problemas. Madrid: ANABAD. 
LOSA SERRANO, P. (1984). Alcaraz en el Antiguo Régimen. Aspectos sociales. En A. Santamaría Conde, L.G. García-Saúco Beléndez (Coords.), Congreso de Historia de Albacete. Vol. 3 (pp. 119-151). Albacete: Instituto de Estudios Albacetenses Don Juan Manuel. MARCOS MARTÍN, A. (1983). De nuevo sobre los diezmos: La documentación decimal de la diócesis de Palencia, problemas que plantea. Investigaciones Históricas. Época Moderna y Contemporánea. (4), 99-122.

MOLINA PUCHE, S. (2005). El gobierno de un territorio de frontera: corregimiento y corregidores de Chinchilla, Villena y las nueve villas, 1586-1690, Investigaciones históricas. Épocas moderna y contemporánea. (25), 55-84.

MOLINA PUCHE, S. (2007a). Como hombres poderosos. Las oligarquías locales del corregimiento de Chinchilla en el siglo XVII. Albacete: Instituto de Estudios Albacetenses Infante Don Juan Manuel.

MOLINA PUCHE, S. (2007b). Poder y familia. Las élites locales del corregimiento de Chinchilla-Villena en el Siglo del Barroco. Murcia-Cuenca, Universidad de Murcia/ Universidad de Castilla La Mancha.

MONTOJO MONTOJO, V. (2007). El archivo objeto de la archivística: El Archivo Histórico Provincial de Murcia en su 50 aniversario, Murgetana Revista de la Real Academia Alfonso X el Sabio. (117), 169-187.

MONTOJO MONTOJO (2018). Notas históricas de linajes de Tobarra y Hellín en 1578-1590, Al-Basit Revista de Estudios Albacetenses. (63), 69-90.

MONTOJO MONTOJO (2019). El corregimiento de Chinchilla de Montearagón en el padrón de 1615 y otras fuentes, Al-Basit Revista de Estudios Albacetenses. (64), 37-70.

MUÑOZ RODRÍGUEZ, J.D. (2010). Felipe $V$ y cien mil murcianos. Movilización social y cambio político en la Corona de Castilla durante la Guerra de Sucesión (1680-1725). (Tesis doctoral). Murcia: Universidad de Murcia.

OLIVARES TEROL, M.J. (1993-1994). Estudio preliminar de la documentación del Archivo de la Catedral de Murcia referente al siglo XVI, Miscelánea Medieval Murciana. (18), 141-160.

PASCUAL GONZALO, B. (2002). Archivo Histórico Provincial de Albacete: nuevas posibilidades de investigación (identificación archivística e historia institucional. En A. Pretel Marín (Coord.). II Congreso de Historia de Albacete. Vol. 4 (pp. 465-479). Albace- 
te: Instituto de Estudios Albacetenses Don Juan Manuel.

PRETEL MARÍN, A. (2019). Alfombras de Alcaraz en casa de un hidalgo de principios del siglo XVI: el bachiller Juan Martínez Guerrero, Al-Basit Revista de Estudios Albacetenses. (64), 5-35.

REY CASTELAO, O. (1992). El reparto social del diezmo en Galicia, Obradoiro de Historia Moderna. (1), 145-162.

REY CASTELAO, O. (1994). Los fundamentos económicos de la Iglesia en la España del período moderno. En V. Suárez Grimón (ed.). III Reunión Científica de Historia Moderna. Vol. 1 (pp. 391408). Las Palmas de Gran Canaria: Universidad de Las Palmas de Gran Canaria.

REY CASTELAO, O. (2010). La financiación de la fábrica catedralicia compostelana, siglos XVII-XIX, Semata: Ciencias sociais e humanidades. (22), 311-328.

RODRÍGUEZ DOMENECH, M.A./RODRÍGUEZ ESPINOSA, E. (2014). El territorio de la Intendencia de La Mancha en el Catastro de Ensenada. Antecedentes, configuración y evolución posterior, Catastro. (80), 89-148.

RODRÍGUEZ DOMINGO, J.M. (2012). Identidad y nobleza de los Pérez Pastor en Guadix, Boletín del Centro Pedro Suárez. (25), 145175.

RODRÍGUEZ DE LA TORRE, F. (1981). Efectos del terremoto de 1 de noviembre de 1755 en localidades de la actual provincia de Albacete, Al-Basit Revista de Estudios Albacetenses. (10), 85-126.

RODRÍGUEZ DE LA TORRE, F. (1984). Noticia de un memorial al Rey Felipe V de los labradores del coto minero de Hellín, hacia 1739. En A. Santamaría Conde, L.G. García-Saúco Beléndez (Coords.), Congreso de Historia de Albacete Vol. 3 (pp. 193-212). Albacete: Instituto de Estudios Albacetenses Don Juan Manuel.

RUIZ IBÁÑEZ, J.J. (1994). Las dos caras de Jano. Monarquía, ciudad e individuo en Murcia (1588-1648). Murcia: Universidad de Murcia

SALOMON, N. (1982). La vida rural castellana en tiempos de Felipe II. Barcelona: Ariel.

SÁNCHEZ GARCÍA, M.A. (2004). Conflictos y abusos de poder en Liétor a mediados del siglo XVIII. En F.J. Aranda Pérez (Coord.). El mundo rural en la España moderna (7a Reunión Científica) Vol. II (pp. 1323-1340). Madrid: Fundación Historia Moderna.

SÁNCHEZ-ROJAS FENOLL, M.C. (1982). El escultor Nicolás de Bussy. Murcia: Universidad de Murcia. 


\section{APÉNDICE DOCUMENTAL}

1. “Vino de Albacete. A una petiçión que presentó Gaspar de Salafranca, mayordomo, sobre el vino de Albacete que está por vender acordaron que el dicho mayordomo todavía haga dilligençia en procurar se venda lo que se pudiere a como pudiere y lo que no se despachare trayendo testimonio se le pasará en quenta": Archivo de la Catedral de Murcia (ACM), Libro 12, Actas Capitulares (Ac.Cap.) 1616-1621, f. 4, 19.8.1616.

2. "Cartas de Caravaca. Y otra de don Luís Ximenez en que daba razón de la probanza que avía hecho en aquella villa contra la encomienda de Calasparra sobre el ganado que allí ervajó el año pasado de la villa de las Peñas pidiendo se le librase lo que se devia de derechos; acordaron se les responda a las dichas cartas y se dé libranza": ACM, Ac.Cap. 1616-1621, f. 5v, 26.8.1616.

3. "Carta de Chinchilla. Leyose una carta de la ciudad de Chinchilla en que pide el trigo de allí que perteneçe al cabildo para repartir entre labradores": ACM, Ac.Cap. 1616-1621/7v, 6.9.1616.

4. "Subsidio y excusado por otro quinquenio: El dicho corregidor don Antonio de Quiñones y por ante Damián de Albornoz, escribano público de esta ciudad, hizo notificar dos mandamientos del señor comisario general, insertos en ellos dos breves de nuestro muy santo padre Paulo papa quinto, de prorrogación del subsidio y excusado por otro quinquenio que empezará a correr el año que viene de 1618; pidiósele traslados de ellos, dexólos": ACM, Ac.Cap. 1616-1621/12, 25.9.1616.

5. "Archivo de fábrica. El señor doctor Cámara canónigo dixo que para hazer un archivo para tener en custodia las escrituras y cuentas de la fábrica se le diese licencia para hazer un cajón para tenellos en la pared detrás de la puerta del cabildo, en el lado del altar por aver allí comodidad, e conferido sobre ello los dichos señores atento que es en utilidad de la iglesia se le dio la dicha licencia": Ídem, 44, 18.11.1616.

6. "Cuentas de Albacete. El señor raçionero Móstoles hizo relaçión como en las quentas que avia tomado Martín Romano a los fieles de los graneros de Albacete y La Gineta eran alcançados en cantidad de maravedíes que avian cobrado, que daua razón de ello para que se viese lo que se avia de hazer; e conferido sobre ello cometieron al dicho señor maestresquela le escriua al dicho Martín Romano agradeçiéndole la diigençia que avia hecho en las dichas 
quentas y procurase hazerla para cobrar los dichos alcançes": Ídem, 47, 2.12.1616.

7. “Agravios del granero de Albacete. El señor maestro Móstoles refirió como el fiel del granero de Albacete le avia dicho avia entregado un memorial de agravios que era neçesario se remediasen en el dicho granero al señor obispo y que su señoría lo avia remitido a su fiel y que él era uno de los culpados, que se viese el orden que se podía tener para su remedio; e votado sobre ello se acordó se le pidiese al dicho fiel otro memorial conforme lo avia dado al señor obispo e cometieron a los señores arcediano de Cartagena y doctor Medina vean el dicho memorial y conforme a él y a lo que an entendido çerca del mal gobierno del dicho granero informen al señor obispo para que procure remediarlo": ACM, Ac.Cap. 1616-1621, 63, 23.2.1617.

8. "Iglesia de Chinchilla. Cometiose al señor arcediano de Cartagena como a fabriquero haga la escritura del concierto con la fábrica de la Iglesia de Chinchilla sobre la deuda que le deue la fábrica de esta Santa Iglesia, puniendo las pagas a los siete plaços que está conçertado son el señor obispo y para ello se le da poder vastante": Idem, 90, 30.6.1617.

9. "Carta de Chinchilla. Leyóse una carta de la ciudad de Chinchilla en que pide se les dé el trigo de aquel granero y se acordó se le responda que a avido mucha necesidad y la tienen los señores de este cabildo para sus casas, que estando proueida se vería lo que conviniese". Ídem, 95v, 18.7.1617.

10. "Ganado de Calasparra: Pedida licencia entró Damián Sánchez, notario, y citó al cabildo con un mandamiento del Deán de la Iglesia de Almería ante quien se an presentado en grado de apelación el comendador y vecinos de la villa de Piego sobre el pleito que con ellos se a traydo sobre el diezmo del ganado del granero de las Peñas de San Pedro; pidiose traslado y que el señor procurador general acuda a ello": Idem, 113 y 114, 19 y 26.9.1617.

11. "Media de Chinchilla. El señor tesorero refirió que en la medida del trigo que se tiene del obispado avia mucho agravio porque en cada fanega de trigo faltaua un çelemín, e conferido sobre ello cometieron al señor raçionero Tizón haga la experiencia de medir la media del granero con la que se mide el trigo que traen que dizen es de Chinchilla y vea lo que va a decir de la una a la otra, y asimismo haga medir todo el pan que oviere en el aposento con la media del granero para ver la falta en que está": ACM, Ac.Cap. 1616-1621/156, 15.12.1617. 
12. "Fiel de Las Peñas. Acordaron que los señores contadores hagan llamar al mayordomo para tratar quien será bien nombrar por fiel en las Peñas de San Pedro atento que no está arrendado": Idem, 184, 23.2.1618.

13. "Colecturía de Las Peñas. Los señores contadores hicieron relaçión de cómo auian hablado al mayordomo en razón de la colecturía de las Peñas y que parecía no auia en aquel lugar a quien poderla dar, si al lcdo. Moreno acordóse se le escriua auise qué fianças tendrá para hacerle el nombramiento": Ídem, 184, 27.2.1618.

14. "Carta de las Peñas. Leyose otra carta del Lcdo. Fco. Moreno, fiel de las tercias de las Peñas, en que da razón que los arrendadores se entrometen a hazer repartimientos de los frutos y a tener llaues en perjuiçio de los interesados; acordaron que el señor procurador general saque mandamiento del provisor para que los dichos arrendadores no se entrometan en la administración y repartimiento de los frutos más de recibir los que les pertenecieren": Ídem, 224, 21.8.1618.

15. "Cartas de los colectores de Yecla y Albacete. Leyéronse dos cartas la una del Lcdo. Pedro Ruiz Puche, colector de Yecla, y la otra de Martín Romano, colector de Albacete, en que decían que Gaspar de Salafranca les executaua por lo que no estauan cumplidos los plaços y otras cosas; cometióse a los señores contadores hiziesen llamar al dicho Gaspar de Salafranca y se le advirtiese de ello": Ídem, $225 \mathrm{v}, 4.9 .1618$.

16. "Langosta de La Gineta: Que el señor maestro Móstoles procurador general escriua al señor don Gabriel de Valcárcel, canónigo, trate en la congregación los agravios que hazen los juezes que vienen a matar la langosta, que no aviéndola en este obispado, an entrado a embarazar en las terçias los diezmos que ay en ellas y echar candados en las puertas y que se saque mandamiento del señor obispo de Aragón para que los ejecutores quiten los candados que an puesto": Idem, 246v, 4.12.1618.

17. "Langosta de las Peñas. Leyose una carta del cura de las Peñas en materia de la langosta que le avia repartido a cabido, cometiese al señor canónigo Islas Tejas vea el repartimiento que el conçejo hizo e conforme a él se le responda al dicho cura". Ídem, 271, 6.4.1619.

18. "Diezmo de los agustinos de Albacete. Leyose una carta de Martín Romano en razón de que los agustinos no quieren pagar diezmo, cometiese al señor procurador general que vea lo que ay sobre esto". Ídem, 287, 13.9.1619. 
19. “Poder a Martín Romano. Otorgaron poder a Martín Romano, presbítero, para que en nombre del cabildo presente testigos en la probanza que se ha de hazer contra los frailes agustinos de Albacete sobre el diezmo de su hacienda": Ídem, 299, 9.7.1619.

20. "Ganado de Albacete. Aviendo entendido que Martín Romano, colector de los dichos señores en la villa de Albacete, avia vendido el grano tocante a los dichos señores a muy bajo precio se acordó se le escriva al dicho Martín Romano para saber con qué orden lo hizo y que no se le pase en cuenta sino al precio a que se vendieron las otras partes de los demás interesados en el granero de la dicha villa": Ídem, 308, 6.12.1619.

21. "Excesos de graneros. Cometióse a señor arcediano de Cartagena sepa de algunos excesos que se dice ay en algunos de los graneros de este obispado particularmente en Almansa y dé razón al cabildo para que se remedie". Ídem, 325v, 14.1.1620.

22. "Carta del Concejo de Las Peñas. Leyóse la carta del Concejo de Las Peñas de San Pedro en que pide la villa se le ayude por parte del cabildo para la matanza de la langosta; cometióse la dicha carta y demás papeles tocantes a esto a los señores arcediano de Cartagena y maestro Móstoles para que con un alcalde ordinario de la dicha villa que a traydo los dichos recados lo comuniquen y siendo suficientes se escriua a el licenciado Moreno para que se halle con los comisarios de la villa a los repartimientos y gastos y que se acuda con la décima parte, conforme es el aprovechamiento de los interesados del granero de la dicha villa”: Ídem, 355, 5.5.1620.

23. "Carta de las Peñas. Leyóse una carta del licenciado Francisco Moreno, clérigo de las Peñas de San Pedro, en respuesta de la que se le escribió en razón de lo que se deue hazer para el repartimiento de la matanza de la langosta de la dicha villa en que da razón de cómo se van haziendo muy grandes repartimientos y pocos gastos y que en lo uno y en lo otro no se halla presente porque se haze todo sin su asistencia; cometióse al señor chantre y a mí el racionero Juan Augustín de Móstoles para que se pida al señor provisor despache mandamientos con penas y censuras para que los comisarios de la dicha villa no hagan repartimiento ni gasto alguno sin asistencia del dicho licenciado Francisco Moreno por los interesados del dicho granero y que haciéndose así se cumplirá con lo que se manda por la provisión de su majestad y se acudirá con la décima parte, conforme al interés que se tiene, que son la décima de los frutos: Ídem, 357v, 15.5.1620.

24. "Langosta de Las Peñas y Chinchilla. Que se escriva al licenciado Francisco Moreno de Las Peñas y al licenciado Alonso Martí- 
nez, arcipreste de Chinchilla, respondiéndoles a sus cartas y enviándoles mandamientos para que los admitan a los repartimientos y quentas del gasto de la langosta": Ídem/359, 22.5.1620.

25. "Carta de Martín Romano. Recibióse una carta de Martín Romano de Albacete sobre la venta del ganado del año pasado de 1619 que pudiéndolo vender al fiado como lo hizieron los demás interesados lo vendió de contado a menos preçio; acordaron se le cargue al mayordomo al preçio que se fió lo demás y en quanto a la langosta que se le emvie mandamiento para que no se haga repartimiento si no fuere con su asistencia y viendo lo que se gasta": Ídem/355v y 359, 5 y 26.5.1620.

26. “Carta a Xaen. Cometióse a los señores canónigo Valcárzel y Doctor Medina para que escriban a Xaen y se sepa el modo que se tuuo en aquella santa iglesia en repartir el susidio y escusado al voto de Santiago y el estado que tiene el pleito que sobre esto ay en el Consejo de Cruzada. Ídem, 356, 8.5.1620.

27. "Voto de Santiago. Que se le dé libranza al secretario de sesenta reales por el trabajo que tuvo en valorar el voto de Santiago de çinco años para cargar el subsidio por quenta del dicho subsidio": Ídem, 360v, 2.6.1620.

28. "Carta de Martín Romano. Leyóse una carta de Martín Romano en que daua razón del repartimiento que avía hecho la justiçia de Albacete de la langosta; acordaron que yo el secretario le responda sobre ello. Ídem, 366, 21.7.1620.

29. “Carta de Martín Romano. Leyóse una carta de Martín Romano en que da razón del repartimiento de la langosta pidiendo orden de lo que a de hazer cerca de ello; acordóse se le responda que la parte que toca al rey se reparta entre los demás interesados en la tercia y todo el repartimiento lo pague por quenta del subsidio excepto lo que está repartido a los clérigos que tienen propiedades que an de pagar de por si; escriuiósele. Idem, 385, 7.8.1620.

30. "Carta a los fieles del obispado. Acordaron se escriua a los fieles colectores del cabildo de la villa de Albacete y otras partes que los diezmos de uva, ganado y lana y otros que se suelen arrendar los arrienden a los plazos ordinarios como lo han hecho hasta aquí y que se le dé razón al mayordomo y yo el secretario se la dí": Ídem, 392v, 18.9.1620.

31. "Petición de los arrendadores de las Peñas: Leyóse una petición de los arrendadores de la renta de las Peñas en que piden se les haga suelta de alguna parte y por lo que quedare se les haga espera atento los malos años y por la langosta que les a destruido los 
frutos; acordóse que se viese e considerase para otro cabildo. Ídem, 399r, 27.10.1620.

32. "Langosta de Las Peñas: Leyóse una carta del licenciado Francisco Moreno en que dize que toca a la parte del cabildo pagar 450 reales por los beneficios que allí tiene para matar la langosta; acordóse se le responda que sepa y averigue toda la cantidad que se a gastado en matarla, porque de todo el gasto se a de sacar la décima parte y esta es la que toca a pagar a los diezmos de la dicha villa sin hazer distinción de beneficios para repartirles de por si y hecha esta diligencia se les librará lo que fuere": Ídem, 399, 27.10.1620.

33. "Leyóse una petición de los arrendadores de las Peñas de San Pedro en que piden espera por dos meses y que el ejecutor que tienen haciéndoles costas se le mande venir. Cometieron a los señores contadores hagan llamar al mayordomo y le hablen para que lo suspenda": Ídem, 399v, 30.10.1620.

34. "Leyóse una carta de Martín Romano en que dize estaua concertada la matanza de la langosta por todos los interesados en los diezmos de la villa de Albacete en mil y quinientos reales; acordaron dé libranza de ellos por quenta del escusado": Ídem, 403, 24.11.1620.

35. “Carta de los arrendadores de las Peñas: Leyóse otra Carta de los arrendadores de las Peñas en que pedían más espera de la que se les avía dado; acordaron que el mayordomo haga diligencia para la cobranza si es pasada la espera que se les dio o quando se pase y no a lugar de más espera": Ídem, 407, 22.12.1620.

36. "Que estando contento y satisfecho el mayordomo con las fianzas dadas por los colectores que pretenden ser de las villas de las Peñas, Tovarra y Cieza se les despachen títulos por escrito y no en otra manera". Ídem, 436v, 7.5.1621.

37. "Que se llame a Pedro de Yepes su mayordomo para esta tarde y que los señores contadores le digan cómo las fianzas de los colectores de Peñas, Tovarra y Cieza an de correr por su cuenta pues él los propuso por su petición y que no an de correr por cuenta del cabildo": Idem, 437, 11.5.1621.

38. "Langosta de las Peñas: Que los señores chantre e Balvás vean los papeles que se an traído çerca de la langosta de las Peñas de San Pedro del año pasado, que se pide por parte de Bartolomé Sánchez y hagan relaçión": Ídem, 441 y 442v, 8 y 18.6.1621.

39. "Viaje de Albacete y carta del señor obispo. El señor Gaspar Ramón Briceño hizo relación del viaje que a hecho a Albacete $\mathrm{y}$ de las diligencias en los negocios a que fue y estado de ellos y se 
leyó una carta que traxo del señor Obispo en que avisa la pretensión de la villa de Albacete. "Cartas de fieles de los graneros: Leyéronse dos cartas, la una del fiel de Chinchilla y la otra del fiel de Albacete, en que dan razón no poder venir ni traer los libros de los diezmos por causas que en ellas expresan; acordaron que acaben de recoger los diezmos y hagan repartimiento de ellos entre los interesados e que no hagan movimiento ninguno hasta que se les avise otra cosa": ACM, Ac.Cap. 1622-1626/49, 19.8.1622.

40. "La ciudad de Chinchilla pide trigo: Leyóse una carta de la ciudad de Chinchilla en que por ella pide se les venda el pan que allí tiene el cabildo y que lo pagarán en buena moneda; acordaron que se les dé la cevada y centeno y el trigo que sobrare tomado el cabildo lo que oviere menester, pagándolo luego y en buena moneda": Ídem, $59 \mathrm{v}, 23.9 .1622$.

41. ": Leyóse una carta del concejo de la villa de Yecla en que piden se le hiziese merced del trigo que allí tenían, e conferido sobre ello acordaron se les responda que el trigo tienen necesidad de él por la falta que hay de él por acá, que se les dará la cevada e çenteno pagándolo luego de contado a la tasa en plata”. Ídem, 63v, 4.11.1622.

42. "Carta de las Peñas: Leyóse una carta de la villa de las Peñas de San Pedro en que piden se les dé el trigo de las tercias para sembrar y repartirlo entre los vecinos de la dicha villa; dixeron se verá lo que se pueda hacer en este particular tomada la razón de su mayordomo de los frutos que ay": Ídem, 68, 6.12.1622.

43. "Corderos de las Peñas. que se escriva a Martín Romano avise siendo informado qué corderos sacan los fieles de todo montón y por qué razón se los reparten son los fieles de las Peñas de San Pedro". ACM, Ac.Cap. 1622-1626/112v, 4.7.1623.

44. "El señor canónigo Balvás hizo relación como el señor tesorero y su merced habían hablado a su señoría en el particular de poner fiel en la tercia de Hellín y que se habían juntado con el provisor de su señoría a conferirlo y asentarlo y habiéndolo comunicado todos tres con su señoría se asentó de la manera que se sigue. No pasó adelante el dicho auto por algunas justas causas que se presentaron". Ídem, 114, 14.7.1623.

45. "Fiel y colector de las Peñas. Confirieron los dichos señores sobre algunas faltas de no buena administración de los diezmos de la villa de las Peñas causadas por el licenciado Moreno y acordaron de despedirlo e que se escriva a Martín Romano, fiel y colector de los diezmos de Albacete, que procure informarse de estas faltas y del precio a como se vendieron los corderos de los demás interesados en la 
tercia de la dicha villa y cometieron a los señores contadores que hagan llamar a Pedro de Yepes para que juntos se informen de persona que pueda servir con seguridad los oficios de colector y fiel que tenía el dicho Francisco Moreno". ACM, Ac.Cap. 1622-1626/111, 27.7.1623.

46. "Sobre la fieldad de las Peñas. Leyóse una carta de Martín Romano en que avisa que el licenciado Andujar, clérigo de las Peñas, es suficiente para cualquiera de los dos oficios de colector y fiel; acordaron se le escriva al dicho Martín Romano le avise que envíe fianzas con un testimonio de abono aprobadas por la justicia de la dicha villa para cualquiera de los dos oficios": ACM, Ac.Cap. 1622$1626 / 118$ y $122,8.8$ y 5.9 .1623$.

47. "Juan Florentín. A una petición de Joan Florentín en que pide lo que ganó en la renta de Montealegre mandaron que se vea lo que ganó": ACM, Ac.Cap. 1622-1626/128, 10.10.1623.

48. "Peñas de San Pedro. Leyóse otra carta del licenciado Moreno de las Peñas; acordaron se le responda que esté a la orden de Martín Romano, fiel de Albacete, así en la entrega de frutos como en lo demás que sobre este particular se ofreciere": Idem, 130, 17.10.1623.

49. "Tercias de Chinchilla y sus aldeas. Leyóse una carta de Rodrigo de Cantos, de Albacete, arrendador de las tercias pertenecientes a su majestad en la ciudad de Chinchilla, sobre los diezmos de las tercias de ella y sus aldeas y mala orden que a avido y ay en la administración de ellos y otras cosas que sobre esta materia advierte; conferido sobre ello se acordó que se le escriva a fiel del cavildo sobre ello y que de aquí adelante los fieles de la dicha ciudad nombren los fieles para el recoger los frutos de las aldeas, con atención a que sean personas de verdad y confianza, y asimismo acordaron se escriva también al señor obispo sobre ello y se le remita la carta del dicho Rodrigo de Cantos para que con acuerdo de su señoría se ponga en este caso el remedio conveniente": ACM, Ac.Cap. 1622$1626 / 130,17.10 .1623$.

50. "Ganado de las Peñas y de Chinchilla: Martín Romano, clérigo colector de Albacete, escrivió una carta a los dichos señores con ciertos papeles que envía con ella sobre el remate del ganado de las Peñas de San Pedro y otros frutos que avía fiado el lcdo. Francisco Moreno y lo que avía fiado Alonso Martínez, colector de Chinchilla, y asimismo avisa el dicho Martín Romano de las fianças que dio Domingo de Gueta para el oficio de colector, que eran bastantes, y asimismo avisa de cómo se puede dar la fieldad de la tercia a Ginés García, al cual nombraron para el dicho oficio" (se le suspendió el 7.11): Ídem, 133, 3.11.1623. 


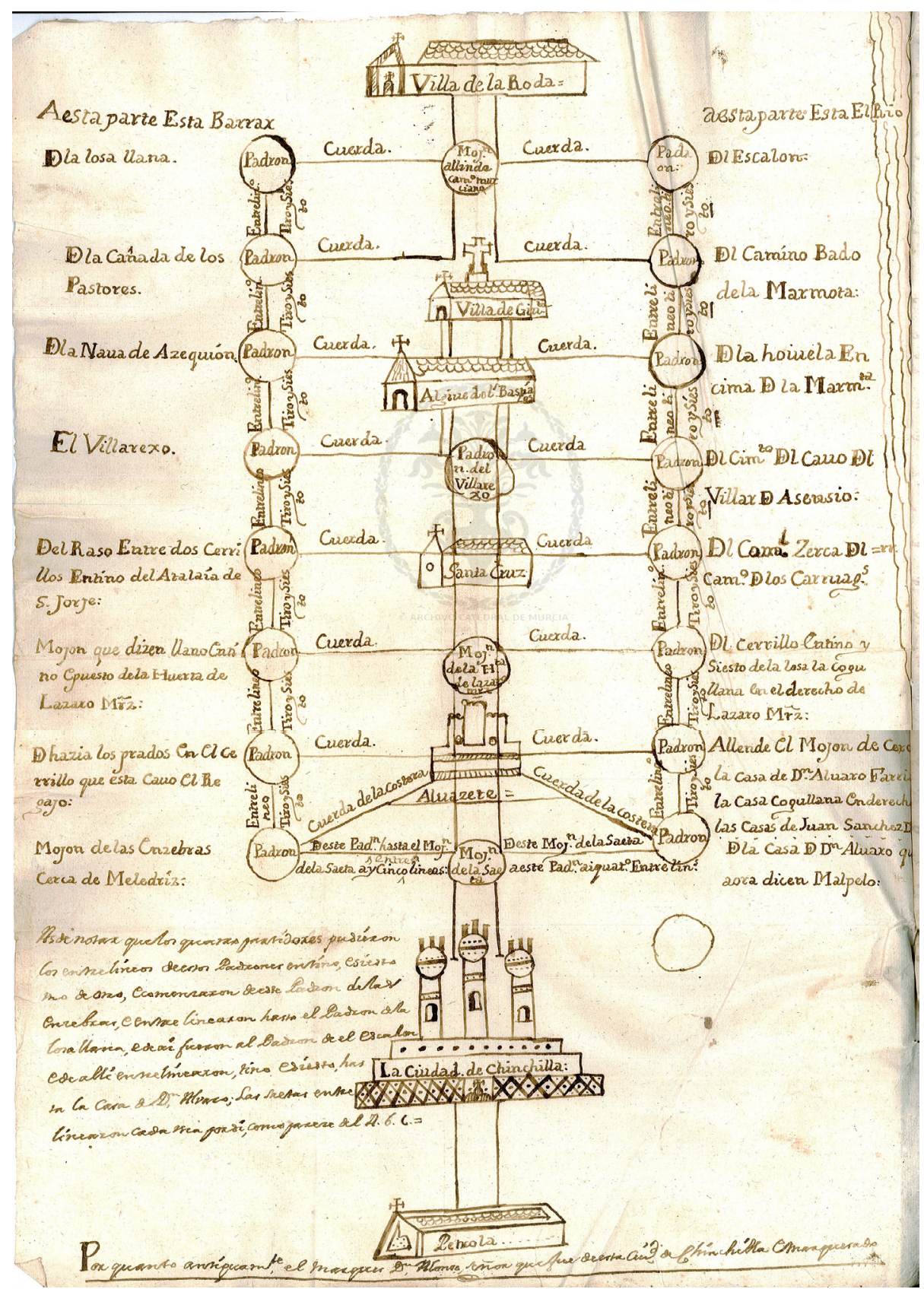




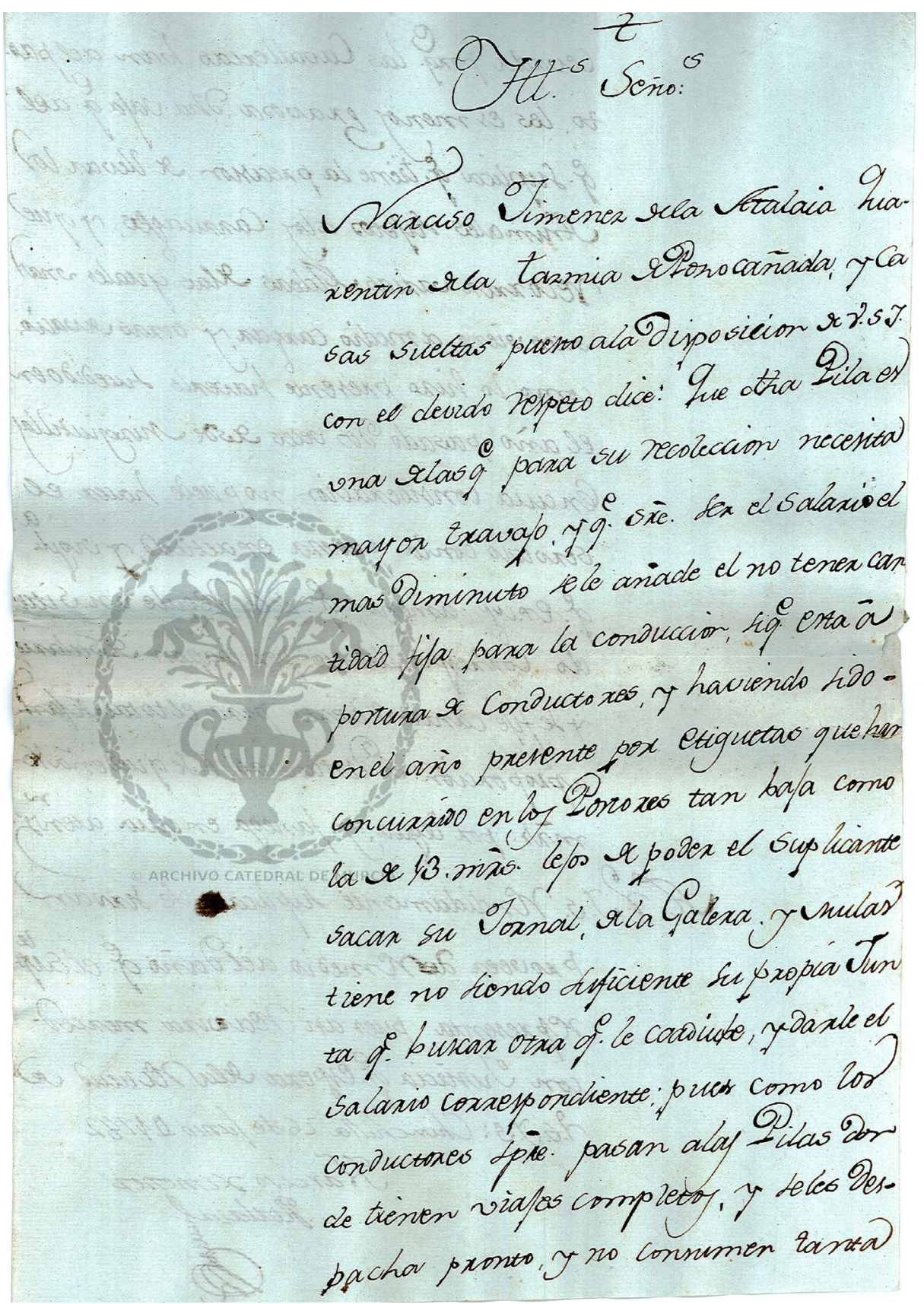




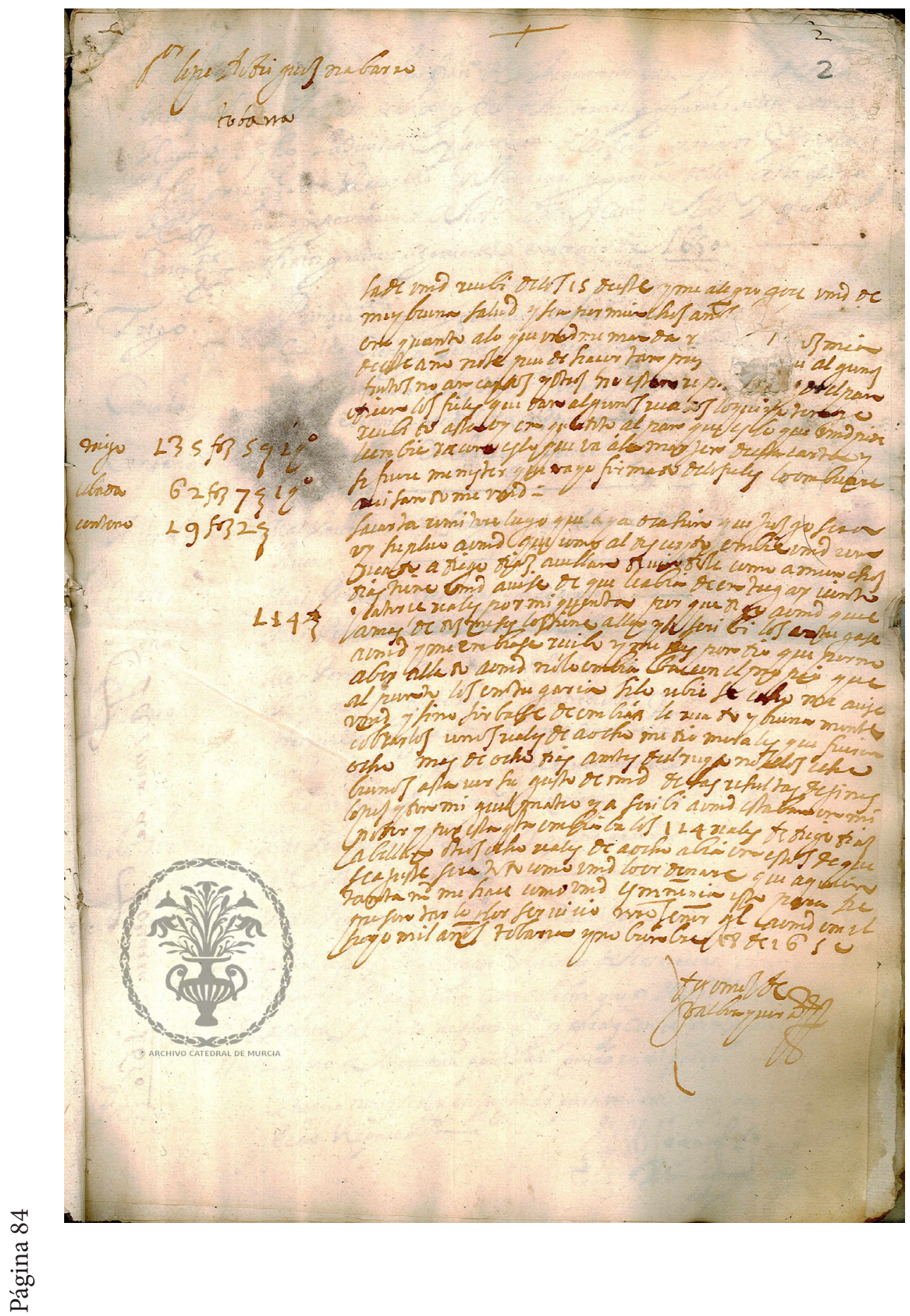

